This manuscript has been submitted for publication in Earth and Planetary Science Letters. Please note that the manuscript has not been peer reviewed yet, hence subsequent versions of this manuscript may have slightly different content. If accepted, the final version of this manuscript will be available via the "Peer reviewed Publication DOI" link on the right-hand side of this webpage.

\title{
Microseismicity appears to outline highly coupled regions on the Central Chile megathrust
}

\author{
C. Sippl ${ }^{1,2}$, M. Moreno ${ }^{3}$, R. Benavente ${ }^{4,5}$
}

\begin{abstract}
The seismogenic zone of subduction zone megathrusts is commonly thought to be made up of frictionally strong patches ("asperities") that rupture in large earthquakes surrounded by weaker regions where a part of the deformation occurs aseismically. Knowledge about the size and location of such asperities can be valuable for hazard estimation purposes as well as for better understanding active processes that occur along the plate interface. We analyzed 4.5 years of seismicity (from mid-2014 to 2018) on the megathrust of Central Chile, obtaining a catalog of 8750 events located with state-of-the art double-difference techniques. Earthquake locations outline three half-ellipse shapes that are open towards the trench, with the northernmost one coinciding with the rupture area of the $2015 M_{w} 8.3$ Illapel earthquake. These elliptical shapes may delineate asperities that concentrate strain build-up in this mature part of the plate interface.

To check whether these shapes indeed outline highly coupled asperities, we combined the seismicity geometries with GPS-based inversions for interplate locking and 3D mechanical models. Prescribing high locking degree to nodes inside the seismicity features, we ran a series of constrained inversions, which achieved data fits comparable to the unconstrained inversion. When trading off data fit against the number of free parameters with the help of the Bayesian Information Criterion, the constrained inversions are even preferred. Locking inversions that make use of seismicity information improve the stability of achieved results and allow to identify locked zones that are not detected by inversions of GPS data alone due to lack of resolution. By using a mechanical frictional model, we simulate the evolution of the state of stress and estimate mechanical coupling on the plate interface throughout a seismic cycle. These mechanical models predict stress concentrations at the downdip edges of highly coupled asperities after prolonged interseismic loading, whose shapes qualitatively correspond to the observed seismicity geometries. The observed narrow trench-perpendicular bands of seismicity that separate aseismic regions in along-strike direction are found to correspond to regions where the subduction of seafloor features may promote a predominance of creep processes.

Our results shed light on the relationship between observed seismicity patterns and the mechanical behavior of asperities. The direct observation of asperities' seismicity signature can independently constrain and thus improve geodetic locking inversions.
\end{abstract}

Keywords:

Subduction Zone, Megathrust, Seismicity, Mogi Doughnut, Segmentation 


\section{Introduction}

Subduction zone megathrusts are segmented in downdip and along-strike direction. Downdip segmentation occurs primarily due to differences in temperature, rheology (Wang et al., 2020), rigidity and possibly pore fluid pressure (e.g. Moreno et al., 2018), which leads to an unstable (velocity-weakening) and thus seismogenic central segment framed by conditionally stable or stable segments above and below (Lay and Kanamori, 1981; Oleskevich et al., 1999; Lay et al., 2012). Large megathrust earthquakes commonly originate on the central, unstable, frictionally resistant part of the plate interface, but occasionally also break the conditionally stable zone above all the way to the trench (like the $2011 M_{w} 9.0$ Tohoku earthquake: Fujiwara et al., 2011; Ide et al., 2011; Lay et al., 2011). The seismogenic central segment is laterally heterogeneous, and consists of frictionally strong and thus highly coupled areas ("asperities") that accumulate stress during the interseismic period, and lowly coupled areas that release part of the plate convergence as aseismic slip (Perfettini et al., 2010). The interseismic locking degree, obtained from modelling interseismic surface velocities (Pacheco et al., 1993; Scholz and Campos, 1995), is a kinematic representation of fault slip that suggests the existence of heterogeneous slip deficit or strain build-up, which shows a general correspondence with slip distributions of large earthquakes (e.g. Moreno et al., 2010; Métois et al., 2012; Chlieh et al., 2011; Loveless and Meade, 2016). Bürgmann et al. (2005), however, have shown that asperities sensu strictu, i.e. patches with full mechanical coupling (= clamped fault areas), can be significantly smaller than the areas that slip in large earthquakes. This shows that the mechanical coupling of asperities can be different from the kinematic locking (distribution of non-slip areas) obtained in backslip inversions (e.g. Wang et al., 2004). Mechanical coupling induces the movement of shallower areas resulting from the deformation halo that produces the constant subduction of the clamped areas (e.g. Moreno et al., 2018), thus invoking slip deficit near the trench, even when kinematic inversions do not detect it. Thus, in this work we use the term "locking" to refer to the degree of slip that can be obtained from inversions of displacements, and "coupling" for mechanical clamping due to the frictional resistance on a fault.

The origin of megathrust asperities, and whether they are long-lived or transient, is currently not understood. The occurrence of regions of higher interseismic coupling and thus higher frictional strength has been ascribed to topographic features on the incoming plate (Sykes, 1971; Cloos, 1992), plate interface curvature (Bletery et al., 2016), variable pore fluid pressure (e.g. Moreno et al., 2014), or combinations of these factors. Highly coupled areas on the megathrust appear to be associated with anomalously low levels of background seismicity, which was already speculated in early studies (e.g. Kanamori, 1981). The Cascadia megathrust, for instance, may be nearly perfectly coupled in its shallow part (Schmalzle et al., 2014) and shows extremely low levels of seismicity (Bostock et al., 2019). Weakly coupled areas that separate asperities can act as barriers to large earthquake ruptures, and there is much debate about whether such rupture barriers are or can be permanent.

In this study, we combine the observation of seismicity patterns with GPS analysis and simple mechanical models for the megathrust of Central Chile to investigate the relation between seismicity patterns and asperities on a mature part of the Central Chilean plate interface. From the analysis of 4.5 years of seismic data, we obtain a high-resolution earthquake catalog that contains $>8,500$ events located on the Central Chile plate interface. These events are not homogeneously distributed, but describe geometries resembling half-ellipses, similar to what has recently been observed for the period before the 2014 Iquique earthquake in Northern Chile (Schurr et al., 2020). In order to check whether the seismicity geometries could outline areas of elevated interplate coupling and thus frictional strength on the megathrust, we use the obtained geometries to constrain GPS inversions for interplate locking and mechanical models of the megathrust.

*corresponding author: sippl@ig.cas.cz; Geofyzikální ústav Akademie věd, v.v.i., Boční II/1401, 14131 Praha 4 - Spořilov, Czech Republic; Tel. +420-267 103386

${ }^{1}$ Institute of Geophysics, Czech Academy of Sciences, Prague, Czech Republic

${ }^{2}$ German Research Centre for Geosciences (GFZ), Section Lithosphere Dynamics, Potsdam, Germany

${ }^{3}$ Departamento de Geofísica, Universidad de Concepción, Concepción, Chile

${ }^{4}$ Departamento de Ingeniería Civil, Universidad Católica de la Santísima Concepción, Concepción, Chile

${ }^{5}$ National Research Center for Integrated Natural Disaster Management (CIGIDEN), Santiago, Chile 


\section{Study area}

The Central Chilean margin is created by the ENE-ward subduction of the Nazca Plate beneath the South American Plate with a velocity of approx. $66 \mathrm{~mm} / \mathrm{yr}$ (e.g. Angermann et al., 1999). The margin is classified as accretionary (von Huene and Scholl, 1991) and features the subduction of two notable seafloor features, the Juan Fernández Ridge at around $32^{\circ} \mathrm{S}$ and the Challenger Fracture Zone at around $30^{\circ} \mathrm{S}$ (Contreras-Reyes and Carrizo, 2011, Figure 2b). Intraslab seismicity (e.g. Anderson et al., 2007; Marot et al., 2013) shows that the Nazca slab transitions from a flat slab configuration (the Pampean flat slab, see e.g. Ramos and Folguera, 2009) to a normally subducting geometry at $32-33^{\circ} \mathrm{S}$ (Figure 1). A causal connection between the subduction of the Juan Fernández Ridge and the formation of the Pampean flat slab has been suggested (Ramos et al., 2002).

Whereas crustal seismicity in most of the Central Chilean forearc is relatively sparse, with most upper plate seismicity confined to the regions adjacent to the Western Cordillera (Barrientos et al., 2004), the Central Chile megathrust has experienced a large number of $M \geq 8$ earthquakes over the past centuries (Figure 2a; Comte and Pardo, 1991; Lomnitz, 2004; Ruiz and Madariaga, 2018). Since the 1730 earthquake that ruptured the entire study area (Carvajal et al., 2017), the pattern of megathrust earthquakes in Central Chile has featured events of limited size (M8-8.5) with relatively stable recurrence in space and time (Ruiz and Madariaga, 2018). The $2015 M_{w} 8.3$ Illapel earthquake was the most recent event in the north of the study area, and occurred where similar-sized events in 1880 and 1943 had been registered (Figure 2a). The northern and southern termination of their rupture areas coincide with where the Challenger Fracture Zone (CFZ) and Juan Fernández Ridge (JFR) are subducted (Tilmann et al., 2016; Lange et al., 2016), consistent with the suggestion that such seafloor features can be efficient rupture barriers along the Chilean margin (e.g. Contreras-Reyes and Carrizo, 2011; Sparkes et al., 2010). Further south, a second series of similar-sized events in 1822, 1906 and 1985 have occurred south of the Juan Fernández Ridge, with no obvious seafloor feature defining their southern termination. To the south, the northern termination of the 2010 Maule earthquake $\left(M_{w} 8.8\right)$ rupture at $\sim 34^{\circ} \mathrm{S}$ (Figure 2b; Moreno et al., 2010; Vigny et al., 2011) marks the end of our study region. It has recently been proposed that the 1985 and 1906 events (and thus likely also the 1822 one) have only ruptured the deeper part of the megathrust (Ruiz and Madariaga, 2018; Bravo et al., 2019), which would imply that the main part of the megathrust in the region between the Illapel and Maule earthquakes (Figure 2b) has been unruptured since 1730.

\section{Seismicity observations}

\subsection{Data and processing}

We analyzed raw waveform data from 32 broadband seismic stations in Central Chile $\left(\sim 29.5-34.5^{\circ} \mathrm{S}\right)$ to derive a microseismicity catalog, applying a modified version of the automated earthquake detection and location workflow of Sippl et al. (2013). The data covers the time period from mid-2014 to the end of 2018, and is available from IRIS webservices (networks C, C1, G, IU, WA; see Acknowledgments). In the initial triggering, event association and repicking stages, the 1D velocity model of Lange et al. (2012) was used, in the later relocation steps it was replaced with a 2D velocity model calculated from a subset of the analyzed data with the simul2000 algorithm (Thurber and Eberhart-Phillips, 1999). The final hypocentral relocation was carried out with the double-difference code hypoDD (Waldhauser and Ellsworth, 2000), in which both catalog traveltime differences $(1,227,880 \mathrm{P}$ and $555,781 \mathrm{~S})$ and cross-correlation lagtimes $(100,873 \mathrm{P}$ and 34,504 ; only if $\mathrm{CC}>0.7$ and distance between event pairs $<15 \mathrm{~km}$ ) were used. RMS residuals of phase arrivals were reduced by $26 \%$ for catalog traveltimes and $80 \%$ for cross-correlation lagtimes during relocation. This procedure yielded a total of 11,788 double-difference relocated earthquakes at depths between 0 and $200 \mathrm{~km}$ (Figure 1), with local magnitudes between 1.4 and 6.5. The catalog is available as a supplementary file to this article.

Since the present study is focused on active processes at the plate interface, we selected only events located at depths of $<60 \mathrm{~km}$ and west of where the slab surface (from the slab2 model; Hayes et al., 2018) reaches $60 \mathrm{~km}$ depth. This leaves a total of 8750 events, which are shown in Figure 2. Relative location uncertainties for these events were determined by bootstrapping and jackknifing tests (Waldhauser and Ellsworth, 
2000 ), in which the robustness of locations relative to the removal of stations (jackknife) and the random perturbation of traveltime differences (bootstrap) are tested. Results of these tests are shown in Figure S1. Relative location uncertainties are smallest in latitudinal and largest in depth direction, which is to be expected considering the event-station geometry (Figure 1). Standard deviations are 1.07/0.49/1.26 km (jackknife) and 2.39/1.14/4.45 km (bootstrap) in east-west, north-south and vertical direction (Figure S1). We also searched for repeating earthquakes in this subset of events. For this purpose, we computed crosscorrelations for event pairs whose epicenters were located at a distance of less than $15 \mathrm{~km}$ from each other, for stations where both events had catalog P-picks. The correlated time windows were 35 seconds long, from 5 seconds before to 30 seconds after the P-pick, which means that they included the S-phase in most cases. The data was bandpass filtered to between 1 and $5 \mathrm{~Hz}$ before the correlation. We defined a pair of earthquakes as belonging to one "repeater family" if they achieved a cross-correlation coefficient of $>0.95$ at two or more stations (Uchida and Matsuzawa, 2013). In Figure 2, we show repeater families with at least three constituent events. We obtained a total of 168 such familes, containing between 3 and 16 repeating earthquakes, all of which show highly similar magnitudes and catalog locations for their constituent events.

\subsection{Results}

A vast majority of the events in our earthquake catalog are located at relatively shallow depths, either offshore or close to the coastline (Figure 1). Since the focus of this study is on the megathrust, we do not further discuss the deeper intraslab earthquakes that clearly depict the transition from a flat to a normally subducting slab across our study region (profiles A-A' and B-B', Figure 1). Figure 2 shows the seismicity at depths of less than $60 \mathrm{~km}$. The profile sections (Figure 1) show that the vast majority of these earthquakes is located very close to the interplate contact, depicted by the slab surface contour from the slab2 model. Focal mechanisms of shallow earthquakes, harvested from the GEOFON and globalCMT databases, show nearly exclusively low-angle thrusting. Taken together, these observations imply that a majority of the events shown in Figure 2 occurred on the plate interface. This is consistent with earlier local-scale studies (Barrientos et al., 2004; Marot et al., 2013) that had a significantly higher station density and thus better location accuracy, and found that upper plate seismicity in the region is rather scarce.

The hypocenters in Figure 2 describe an along-strike continuous band at depths of 30-45 km, located just west of the coastline, which supposedly coincides with the downdip limit of interplate coupling along most of the South American margin (Chlieh et al., 2004; Béjar-Pizarro et al., 2013). Further updip, seismicity is confined to narrow, highly active "fingers" that extend towards depths as shallow as $\sim 10-15 \mathrm{~km}$ and separate larger, aseismic areas on the shallow megathrust. This leads to the appearance of three halfellipses, open towards the trench, that are outlined by seismicity. The north-south band of events west of the trench comprises activity along the outer rise region. The northernmost of the three identified half-ellipses corresponds remarkingly well to the extent of slip during the $2015 \mathrm{Mw} 8.3$ Illapel earthquake (Tilmann et al., 2016). The other two half-ellipses are confined to the region between the rupture areas of the 2015 Illapel and the 2010 Maule earthquakes, where the megathrust may not have been ruptured since 1730 (see Section 2). The region north of where the Illapel earthquake occurred shows more widespread seismicity that also extends to the shallower part of the plate interface (Figure 2b). Repeating earthquakes of relatively low magnitude (usually $\mathrm{M} \leq 3.5$ ) are found in several clusters, the most prominent of which is the so-called Vichuquén cluster in the south of our study area, a well-known feature of locally increased seismicity rate on the deep part of the plate interface around $34.7^{\circ} \mathrm{S}$. A high concentration of repeaters is also found in the region of the 2017 Valparaíso earthquake sequence, on the deeper part of the plate interface around $30.7^{\circ} \mathrm{S}$, and on the northern seismicity "finger". It is notable that the region of the 2017 Valparaíso sequence (Ruiz et al., 2017) became active in 2015, during the Illapel earthquake sequence, although it is located $>100 \mathrm{~km}$ south of the area of rupture. Most of the highly active band of seismicity at $30-45 \mathrm{~km}$ depth (except for the aforementioned clusters) shows only very few repeating earthquakes.

Due to a station distribution that is highly variable in space (much denser around Santiago de Chile; see Figure 1) and time (significantly fewer stations in the years 2014 and 2015), determining a single completeness magnitude for the catalog is not meaningful. Considering earthquake magnitudes in the seismicity "fingers" 
as well as for the outer rise region, we think that the imaged aseismic regions on the megathrust did not feature earthquakes of $\mathrm{M}>3$ during our observation period.

\section{Locking models derived from GPS data}

\subsection{Data and unconstrained inversion}

We used a kinematic inversion based on measured GPS velocities to estimate the degree of kinematic locking on the plate interface. We applied the back-slip modelling approach (Savage, 1983), in which the continuous relative plate motion is accommodated by non-slipping (locked) and aseismically slipping zones on the interface. The fault locking is described as the fraction of plate convergence not accommodated by aseismic slip between great earthquakes. It is calculated by dividing the estimated back-slip rate by the plate convergence rate, which is $\sim 66 \mathrm{~mm} / \mathrm{yr}$ in the study area (Angermann et al., 1999; Kendrick et al., 2003). Thus, the degree of locking ranges from 0 for areas where the entire plate convergence is accommodated by free slip, to 1 for completely non-slipping, i.e. fully coupled, patches. As input for the inversion, we used a set of 186 horizontal (north and east components) published GPS vectors (Figure 3a; Klotz et al., 2001; Brooks et al., 2003; Vigny et al., 2009) that cover the forearc, arc and even extend into the backarc along the entire along-strike extent of the inversion grid. We transformed these velocities to a stable South American continent reference frame. These data were acquired in the decade before the 2010 earthquake, the last time when Central Chile was completely in the interseismic period and no major overprinting of GPS velocities by postseismic processes occurred. Since then, the areas of the 2010 Maule earthquake $\left(M_{w} 8.8\right)$ and the 2015 Illapel earthquake $\left(M_{w} 8.3\right)$ have ruptured, and their postseismic relaxation processes contaminate the GPS velocity field to this day. We attempted to use current GPS data recorded contemporaneously with the seismicity, but postseismic contamination in the vicinity of these two earthquake areas prevented us from retrieving reliable locking models. However, we believe that the size and position of asperities, especially in the areas that did not rupture, should not experience significant changes within a decade.

We used 3D-spherical viscoelastic finite-element models (FEMs) and built viscoelastic Green's Functions (GFs) following the method of Li et al. (2015). For more details on the FEMs, as well as the utilized rheological properties, the reader is referred to Section 5. The inversion was performed on the fault nodes located at a depth of less than $70 \mathrm{~km}$, yielding a total of 353 nodes. We estimated the GFs for the downdip and along-strike components using Pylith (Aagaard et al., 2013). At the bottom edge of the fault plane (70 km depth), we constrained the back slip to zero, assuming aseismic slip below the seismogenic zone. Minimum and maximum slip constraints are applied to avoid models with unreasonable slip patterns and to improve the model resolution. Thus, the back-slip rate is constrained to range between 0 and $66 \mathrm{~mm} / \mathrm{yr}$, representing freely slipping and fully coupled areas, respectively. The smoothing parameter, $\beta$, is estimated from the trade-off curve between misfit and slip roughness. The inversion is stabilized by utilizing Laplacian smoothing regularization with observations being weighted according to the reported station measurement error (usually $\sim 2 \mathrm{~mm} / \mathrm{yr}$ ). The optimal solution (shown in Figure $3 \mathrm{~b}$ ) is then found by employing a bounded least squares scheme.

\subsection{Constrained inversions}

Locking patterns derived from interseismic geodesy show heterogeneous plate interfaces with anomalies that mostly correlate with coseismic slip distributions (e.g. Chlieh et al., 2008; Moreno et al., 2010; Loveless and Meade, 2016). They can thus identify areas with high slip deficit. However, such locking estimates are highly dependent on amount and distribution of geodetic data, modeling assumptions and inversion technique. Thus, even locking distributions for the same area calculated with similar data can differ significantly (e.g. Moreno et al., 2010; Métois et al., 2012; Chlieh et al., 2011; Schurr et al., 2014). If the seismicity pattern we observe outlines non-slipping asperities, then the seismicity offers additional and independent information that could be used to improve GPS-based locking inversions. 
To test whether the half-ellipse shapes in Figure 2 could correspond to highly locked asperities, we thus digitized potential asperity shapes outlined by microseismicity, to then check if the GPS data are compatible with their existence. To explore the size of these possible asperities, we considered three possibilities for their geometry towards the trench: 1) minimum sized asperities, with their limits inside of the seismically active area; 2) normal sized asperities, with their limits in the center of the seismicity structures and closing the asperity normally; 3) maximum sized asperities extending all the way up to the trench (see Figure 4a). For our constrained inversions, we then fixed the grid nodes located inside these asperity realizations (Figure 4b) to different locking values, only inverting for the optimal distribution of interplate locking on the remainder of grid nodes.

In a first run, we fixed the nodes from the different asperity estimates to full locking (i.e. backslip rate $=$ plate velocity). Fixing them excludes these nodes from the optimization process. All other inversion parameters, such as the utilized data or Green's Functions, were the same as for the unconstrained inversion, but since the number of free parameters differed, we determined new optimal smoothing parameters $(\beta)$. In order to compare the results of these inversions to the unconstrained inversion, we assessed their statistical significance using the Bayesian Information Criterion (BIC; Schwarz, 1978). The BIC allows a comparison between models with different numbers of parameters; the model with a lower BIC should be preferred. Assuming Gaussian data errors and omitting a constant term, the BIC can be expressed as

$$
B I C=\chi^{2}+M \ln (N),
$$

where $N$ is the number of data points, $M$ the number of parameters and

$$
\chi^{2}=(\mathbf{d}-\mathbf{G} \hat{\mathbf{m}})^{T} \mathbf{C}_{d}^{-1}(\mathbf{d}-\mathbf{G} \hat{\mathbf{m}})
$$

is the chi-square misfit. Here, $\mathbf{d}$ and $\hat{\mathbf{m}}$ are the data and optimal parameter vectors, respectively; and $\mathbf{G}$ is the GFs matrix. It is clear from equation 1 that the BIC will trade-off model complexity (quantified by $M$ ) with misfit (quantified by $\chi^{2}$ ). We assumed a diagonal data covariance matrix $\mathbf{C}_{d}$, that is, no correlations are prescribed between data errors. The elements of $\mathbf{C}_{d}$ are $\sigma_{i}^{2}$, where $\sigma_{i}$ is the error for the $i$-th datum. We assume that data errors are dominant and assign $\sigma_{i}$ to the GPS measurement errors.

\subsection{Results}

The optimum unconstrained locking model we derived is shown in Figure 3b. It features a highly locked region in the south, roughly coinciding with the source region of the 2010 Maule earthquake, and a region of overall low locking north of $30.5^{\circ} \mathrm{S}$. Between these regions, the overlay with the seismicity (Figure 3) shows no clear correspondence between the seismicity half-ellipses and highly locked patches, which would be expected if the seismicity indeed outlines regions of elevated frictional strength. However, the resolution of the locking map is limited (see checkerboard tests in Figure S3), especially in the offshore regions. The constrained inversions (Figure 5) are thus used to explore whether locking distributions that assume the existence of such asperities are compatible with the GPS data.

When assuming full locking, the largest asperity size that extends all the way to the trench receives a BIC similar to (but very slightly lower than) the unconstrained inversion, whereas both other geometries are clearly preferred compared to the unconstrained inversion according to the BIC criterion (see Figure 5). We extended the analysis by also varying the prescribed locking degree for the three asperity parameterizations. For each series of inversions with the same asperity size, the number of parameters is constant, so that variations of the BIC are purely due to differences in the $\chi^{2}$ misfit. For all three asperity realizations, a clear preference of higher locking degrees is visible from the BIC plot. When the same number of nodes is fixed elsewhere along-strike, the BIC minimum is situated at a significantly lower locking percentage (Figure S6) and is less pronounced than the overall minimum obtained with the original asperity configuration. This indicates that the data are sensitive to the along-strike location of highly locked regions, with the location 
derived from microseismicity being preferred.

The minima for the three asperity sizes are situated at locking values of 0.68 (maximum asperities), 0.74 (normal asperities) and 0.78 (minimum asperities). The global minimum BIC is reached by the largest asperity realization (i.e. with the largest number of fixed parameters), which is likely due to the combination of a generally underdetermined inversion and low resolution towards the trench (see Figure S3). Changes of the model in the offshore region will not have a large effect on the achieved misfit due to the inherently low resolving power there, so the BIC criterion will always favor a reduction of free parameters. Comparing data misfits and BIC values, it appears that a number of scenarios including highly locked asperities inside the half-ellipses outlined by the earthquakes can be fit well by the GPS data. Note that RMS data misfits of the optimum constrained models (Figure 5, upper row) are nearly identical to the one for the unconstrained inversion $(3.73 \mathrm{~mm} / \mathrm{yr}$; see Figure 9$)$. While the unconstrained model shows a locking distribution with regions of higher locking that coincides with the region of elevated background microseismicity at depths of $30-45 \mathrm{~km}$ (especially around $32^{\circ} \mathrm{S}$ ), the data can be fit equally well by models that concentrate locking further updip, inside the asperity shapes we introduced.

\section{Stress modelling}

\subsection{Approach}

The interseismic locking degree, obtained from the inversion of elastic dislocation modeling of surface velocities, is a purely kinematic representation that suggests heterogeneous fault slip rates but does not provide direct information about the stress distribution. Shear stress (traction) estimated based on kinematic models represents an abrupt static change from positive to negative values at the edges of the highly locked zone (Figure S4, left). Therefore, it cannot be used to estimate the degree of slip of the shallowest parts of the fault, which is generally not well resolved by the inversion. By using a frictional model (Figure S4, right), we can simulate the evolution of the state of stress on the plate interface and estimate mechanical coupling (Scholz, 1998; Wang and Dixon, 2004) also in areas that are not well-resolved in kinematic inversions (Almeida et al., 2018).

To better understand what physical mechanism could be responsible for our seismicity observations, we conducted a set of mechanical experiments. Although our model is simple, it helps to understand the stress build-up around a clamped zone (asperity) with higher frictional resistance that is continuously subducted at a time scale of decades. Our mechanical frictional model is meant to explore how the asperities suggested by the distribution of seismicity represent the displacement as shown by GPS and stress loading on the plate interface. To simulate the steady interseismic subduction of the oceanic plate, we specified two fault interfaces with kinematic conditions along the entire base of the oceanic crust and on the top of the slab below the seismogenic zone (Figure 6a). On those interfaces, we prescribed homogeneous creep at a constant rate equal to the plate convergence velocity (66 mm/yr; Angermann et al., 1999), but with opposite sign. We specified a frictional fault interface in the seismogenic zone (up to $65 \mathrm{~km}$ depth) with the Coulomb failure criterion: $\tau=\mu *(\sigma n)+c$, where $\tau$ is the shear strength of the fault, $\mu^{\prime}$ is the effective friction coefficient, $\sigma \mathrm{n}$ is the fault normal stress and $c$ is the cohesion. For simplicity, our model neglects gravity body force but specifies normal tractions consistent with the overburden (lithostatic load) as initial stress state along the frictional fault. Fault slip occurs when the driving forces exceed $\tau$. The final models were three-dimensional spherical Finite Element Models (FEMs) that include topography and bathymetry, as well as a realistic geometry of the slab and continental Moho (Tassara and Echaurren, 2012; Hayes et al., 2012). Our geomechanical simulations are solved using the open source finite element code PyLith (Aagaard et al., 2013). Our models consist of an elastic downgoing slab unit (oceanic plate) and an upper plate unit (overriding continental plate). We specified a Young's modulus of 100,120 and $160 \mathrm{GPa}$, for the continental, oceanic, and mantle layers, respectively (e.g. Moreno et al., 2011). The Poisson's ratio was set to 0.265 for the continental and to 0.30 for the oceanic crust. The thickness of the oceanic plate was set to $30 \mathrm{~km}$ (e.g. Moreno et al., 2011). Density values of 2,700 and $3,300 \mathrm{~kg} / \mathrm{m}^{3}$ are used for the continental and oceanic layers, respectively. 
We simulate the mechanical behavior of coupled asperities by clamping the sections of the fault (equivalent to the approach in Moreno et al., 2018) equivalent to the previously obtained asperity outlines (Figure 4b). This means we set a higher coefficient of effective friction there than for the rest of the fault. Consequently, the asperities remain clamped (no sliding) until the frictional forces overcome the fault strength and the coupled section begins to slide. Aseismic slip occurs at areas with a lower effective coefficient of friction surrounding the asperities. These frictionally clamped areas represent regions of mechanical coupling, which slide as stresses increase. Such decoupling initiates at the edges of the clamped areas, where the largest stresses accumulate (Figure 7). These relatively simple models are designed to qualitatively understand the accumulation of shear traction through a seismic cycle in the presence of heterogeneous frictional strength, and the resulting interplate coupling patterns. Due to the imposed simplified rheology, they are not capable of creating a realistic representation of the complex processes that occur in the time period directly before and during a major earthquake (such as creep transients, fault acceleration, nucleation phases etc.). We recognize that more complex frictional laws would allow a better understanding of the dynamics of the asperities. However, the complexity of modeling with other frictional laws (e.g. rate-and-state law) would represent a great effort on its own.

\subsection{Results}

The size of the coupled asperity and the frictional contrast around the asperity should be the main controls on both the pattern of stress concentration downdip and the time when a fault segment begins sliding without building extra stress. For each of the geometries, we thus tested a wide range of frictional contrasts between the asperities and the surrounding areas. Figure 7 shows the exemplary temporal evolution of one specific model. At each timestep, we obtained the distribution of accumulated shear traction as well as a coupling map (Figure 6b,c) that shows where fault motion in response to reaching the critical stress threshold has occurred. We calculated synthetic crustal motion values for all GPS stations from these coupling maps and can thus evaluate residuals relative to GPS observations.

The model in Figure 7 shows the gradual accumulation of shear traction that is concentrated inside the clamped assumed asperities. Inside the asperities as well as on the remainder of the fault, stress concentrates in the downdip part, whereas a "stress shadow" is observed further updip. With increasing interseismic loading through time, the weaker non-asperity parts of the fault start creeping, which causes diminishing coupling estimates. At the 100 yrs timestep, the entire fault is perfectly coupled (the stress threshold has not been reached anywhere), which does not agree with GPS observations (large trenchward residuals). GPS residuals gradually decrease from timestep to timestep, together with a growing amount of creep on the non-asperity fault segments. From about 250 yrs onwards, some creep also initiates inside the asperities, decreasing their coupling and eventually reversing the GPS residuals (350 yrs timestep).

We chose to concentrate on the $300 \mathrm{yrs}$ timestep, since the last complete rupture of the Central Chilean megathrust occurred 290 years ago (1730 earthquake; see Section 2 and Figure 2b). We systematically varied the ratio of the effective friction coefficients between the fault sections outside $(\mu 1)$ and inside $(\mu 2)$ the asperities by fixing a constant effective friction coefficient of 0.04 inside the asperities (based on Moreno et al., 2018) and changing the friction coefficient value for the remainder of the fault. Results from this exercise are shown in Figure 8. The coupling model based on the normal sized asperities reproduces the GPS observations best. In this configuration, the optimal ratio of effective friction coefficients is $\sim 0.05-0.1$. Despite being a very simple forward model, the optimal model represents the observed GPS velocity field surprisingly well, achieving an RMS residual of only $4.88 \mathrm{~mm} / \mathrm{yr}$ (Figure 9). The greatest misfit to the data is seen in areas far from the coast, indicating that the coupled area could extend to deeper depths in reality and/or that the effect of continental deformation is not accounted for in our model. The model with the normal sized asperities reaches a predicted concentration of stress of $\sim 6 \mathrm{MPa}$ after $300 \mathrm{yrs}$ of loading. The degree of slip on the fault indicates that the asperities are more than $80 \%$ coupled, and that the coupling extends to the trench (Figure 6b,c).

The maximum-sized asperities stay coupled for a longer time period before reaching the critical failure state, whereas the smallest asperities are decoupled after a shorter time (Figure 8). Accordingly, we find that the 
minimum sized asperities after 300 yrs are only 50\% coupled when assuming a frictional ratio around 0.1, inducing lower surface displacements than what is observed with GPS. This can be compensated by higher frictional ratios (optimum at 0.2 ; see Figure 8). The maximum sized asperities are still fully coupled after 300 yrs, producing larger deformation than is observed by the GPS data. Even for the lowest frictional ratio we tested, their curve (Figure 8, lower right) does not define a minimum, which implies that such large areas of increased frictional strength are not compatible with GPS observations. In all simulated scenarios, it would be possible to further improve the fit to the data by experimenting with how exactly the geometry of the asperities is derived from the seismicity distribution. Despite being a very simple forward model, our approach represents the field of velocities observed by GPS quite well, which is useful to define a range of possible asperity sizes and to understand their mechanical coupling behavior. However, inverting slip deficits with mechanical models is not simple; since the degree of mechanical coupling is time dependent, it would require the implementation of non-linear inversion methods.

\section{Discussion}

Through a combination of seismicity observations with GPS-based plate interface inversions for the locking degree and 3D mechanical models, we have shown that the half-ellipse patterns on the Central Chile megathrust likely outline regions of elevated interplate locking due to clamped zones ("asperities") with higher frictional resistance. This implies that incorporating seismicity information can be a way forward in achieving higher resolution interplate locking maps, especially in the usually badly resolved offshore regions close to the trench. Here, we will first discuss the physics of microseismicity generation at the downdip (Section 6.1) and along-strike edges (Section 6.2) of highly coupled regions on the megathrust. Lastly, the question whether these seismicity features are confined to specific stages of the seismic cycle is debated (Section 6.3).

\subsection{Deep interface seismicity as consequence of stress accumulation at asperity edges}

With a simple mechanical model setup using realistic geometries and plate velocity conditions (Figures $6,8)$, we were able to retrieve distributions of shear stress accumulation where concentrations of stress correspond to where seismicity is observed on the Central Chile megathrust (Figure 6), and predicted upper plate deformation from these models fits GPS observations reasonably well (Figure 9). The physical process demonstrated by our models has already been shown and discussed in Dmowska and Li (1982) and Schurr et al. (2020) for the case of a single asperity surrounded by weaker material capable of releasing part of the interseismic loading through creep. Our present results extend this to the case of several (here: three) asperities in a line setup, two of them in a region that is considered to be in the late part of the interseismic stage.

As shown in Section 5, the presence of strong regions on the megathrust leads to stress concentrations at their downdip edges, whereas the weaker regions around them release part of the interseismic loading through aseismic creep. Frictionally strong regions show no seismicity, since near-perfect coupling precludes relative movement before reaching the critical stress threshold (see Figures 2b, 6b). In contrast, creeping areas on the megathrust promote microearthquake activity, since multi-scale heterogeneity on the fault surface means that small patches of stick-slip motion will always be present in regions that are largely deforming aseismically. At the downdip edge of highly coupled areas, creep processes will also set in towards the end of the seismic cycle, when a stress threshold is reached (Figure 7, time steps of 300 and 350 years). This creep drives the observed seismicity in the most highly stressed regions of the asperities.

Slight discrepancies between the location of seismicity and predicted stress concentrations (Figure 6b) likely derive from some of the simplifications that we employed, such as the arbitrary definition of where the asperities terminate (Figure 4), or the prescription of homogeneous coupling inside asperities. In nature, the edge of an asperity would probably feature a gradient of frictional strength rather than a discrete jump, which would lead to a broader region of stress concentration. Our model describes the mechanics of stress loading around asperities, a pattern that coincides with microseismicity concentration. This supports the definition 
of geometries based on seismicity distribution to constrain locking degree inversions with independent information better. The presented models provide an understanding of the mechanical relationship between seismicity and asperities, but they do not detail how changes in stress, transient events, or fluid pressure can trigger the final rupture in the center of the asperities. However, we expect that these observations can motivate further work based on more complex friction laws (e.g. Barbot, 2019).

\subsection{The nature of the along-strike separators}

While the buildup of shear traction at the downdip end of highly coupled areas on the megathrust provides an explanation for the observed band of microseismicity at depths of 30-45 km, no corresponding increase of shear traction is obtained where the seismicity "fingers" separate the different aseismic regions on the megathrust in along-strike direction (Figure 2b). Understanding why and where these separators occur is crucial, since they appear to prescribe or at least image the along-strike segmentation of the Central Chilean plate interface.

Along-strike changes in the behaviour of the plate interface are thought to be primarily controlled by plate interface roughness, which is often a consequence of the subduction of seafloor relief (Contreras-Reyes and Carrizo, 2011; Bassett and Watts, 2015; van Rijsingen et al., 2019). Clearly identifiable seafloor features, the Challenger Fracture Zone to the north and the Juan Fernández Ridge to the south (marked in Figure 2b; shown in more detail in Figure S2), likely acted as delimiters of the 2015 Illapel earthquake (Figure 2b Tilmann et al., 2016; Lange et al., 2016; Poli et al., 2017). The microseismicity extending to shallow depths we observe both north and south of the Illapel rupture (Figure 2b,c) could thus be linked to the ongoing subduction of these features. The southern separator, located at $\sim 33^{\circ} \mathrm{S}$, is situated where the incoming Nazca plate has been classified as smooth in a larger-scale study (Lallemand et al., 2018), but on a more local scale it is observed where the San Antonio seamount is currently being subducted (Ruiz et al., 2018). While individual subducting seamounts often have their own microseismicity signature (e.g. Sun et al., 2020), locally or regionally increased lower plate roughness leads to reduced interplate coupling and a larger proportion of aseismic creep (Wang and Bilek, 2014). This fits well to our observation that the seismicity "fingers" we retrieve show a larger quantity of repeating earthquakes compared to most regions further downdip (Figure 2b,c; see observations in Poli et al., 2017; Ruiz et al., 2017). Events with highly similar waveforms are a consequence of ongoing aseismic creep processes driving seismic slip on many small coupled patches along the heterogeneous plate interface (Nadeau and McEvilly, 1999; Uchida and Bürgmann, 2019). While the available maps of interplate locking (Figure 3b) do not have sufficient resolution to show reduced locking along such narrow segments (Figure S3), the region north of the 2015 Illapel earthquake (north of $30.5^{\circ}$ ) shows lower interplate locking (Figure 3b; Métois et al., 2012) accompanied by widespread seismicity along the entire plate interface (Figure $2 \mathrm{~b}, \mathrm{c}$ ).

Figure 2c shows that most of the seismicity along the separators is episodic and part of major earthquake sequences, the 2015 Illapel earthquake sequence for the northern and the 2017 Valparaíso earthquake sequence for the southern such "finger". However, there is evidence for swarm-like earthquake sequences north and south of the later Illapel rupture in the decades before its rupture (Poli et al., 2017) as well as at $\sim 33^{\circ} \mathrm{S}$ in the years before the Maule earthquake (Holtkamp and Brudzinski, 2014). Both separators can be recognized in seismicity plots of the CSN earthquake catalog covering the time before 2014 (see, e.g., Figure 2 in Métois et al., 2016). Moreover, Figure 2c shows that some repeating earthquakes are observed from mid-2014 (i.e. before the large earthquakes) in both separators, and that seismicity in the area of the 2017 Valparaíso earthquake was activated during the Illapel sequence further north. The 2017 Valparaíso sequence itself was preceded by transient deformation recognized in GPS data as well as a foreshock sequence (Ruiz et al., 2017).

In summary, it appears that the narrow "fingers" of seismicity we retrieved are the signatures of locally decreased interplate locking and thus increased aseismic creep, which occurs where rough and/or more highly hydrated regions on the downgoing plate are subducted. These features are intermittently active during the interseismic stage and more strongly active in the postseismic stage of one of the adjacent asperities. Given a long enough observation timespan in the interseismic period, the seismicity distribution resembles the postseismic one (where event rates are much higher), which implies that the structure of the lower plate is the main control on these localized separators (as also argued in Agurto-Detzel et al., 2019). It is highly 
important to better characterize these regions, since their widths relative to the highly coupled areas as well as the proportion of aseismic creep they host determine their efficiency as barriers to large earthquakes (e.g. Corbi et al., 2017).

\subsection{Mogi Doughnuts and the temporal evolution of seismicity patterns on the megathrust}

Pre-seismic quiescence in the later slip region, accompanied by increased seismicity levels in a ring or half-ring shape around it, has been first observed more than five decades ago (Mogi, 1969, 1979; Kanamori, 1981). Although such "Mogi doughnuts" have been later also been predicted with mechanical models (e.g. Dmowska and Li, 1982) and observed in rock mechanics experiments (Goebel et al., 2012), only very few clear observations of Mogi doughnuts have been made to date (e.g. Schurr et al., 2020). In contrast, observations of aftershock seismicity surrounding the main shock slip areas are well established (Das and Henry, 2003). The reason for this may lie in the temporal evolution of seismicity, which appears to be markedly different for the downdip edges of highly coupled regions (Section 6.1) and the along-strike separators (Section 6.2). We have shown that interseismic loading of asperities (i.e. regions of increased frictional strength on the megathrust) naturally results in concentrations of shear traction at their downdip edges (Figures 7,8$)$. It is likely that microseismicity at the loci of stress concentration only commences once a stress threshold level has been reached, i.e. only at fault segments relatively late in their interseismic stage. Then, seismicity in these regions appears to be continuous (Figure 2c). Observations of such bands of seismicity located around the downdip termination of highly coupled regions are not uncommon (e.g. Feng et al., 2012; Ader et al., 2012; Yarce et al., 2019). The along-strike separators, in contrast, are only active in episodically occurring bursts (Figure 2c), most prominently when activated by nearby events (similar to observations of Schurr et al., 2020). This means that studies of only a few years of seismicity (like ours) may or may not observe the signature of such separators. Unlike the band of deeper interface seismicity, they feature large amounts of repeating earthquakes that occur as a consequence of aseismic creep. Long-term studies of repeating earthquakes have shown clusters of such events downdip and at the along-strike terminations of later megathrust earthquakes (e.g. Uchida and Matsuzawa, 2013). These observations may be due to the erosion of coupled asperities by creep processes that have been shown in rate-and-state simulations (Mavrommatis et al., 2017; Jiang and Lapusta, 2017). The large acceleration of aseismic processes in the postseismic stage (Perfettini et al., 2010) then evokes a higher rate of microseismicity in these mostly creeping regions, which allows the clear identification of such separators close to the main shock area during aftershock series. A recent example is the area of the $2016 M_{w} 7.8$ Pedernales earthquake, where the main shock that was situated on the deeper part of the megathrust activated three narrow seismicity "fingers" separating largely aseismic regions in the presumably unruptured part of the megathrust (Agurto-Detzel et al., 2019; Soto-Cordero et al., 2020). As in Central Chile, these features can be correlated with incoming seafloor relief.

For Central Chile, our results imply that two adjacent, mature asperities are possibly present between the rupture areas of the 2015 Illapel and the 2010 Maule earthquake (see Figure 2b). These asperities may have accumulated stress for nearly 300 years. The imaged barrier between them, highlighted by the 2017 Valparaíso earthquake sequence (Figure 2b,c), likely mechanically controls whether they will rupture jointly or individually, and thus the size of a future earthquake.

\section{Conclusions}

We discovered a seismicity pattern consisting of three half-ellipses, open in trench direction, on the Central Chile megathrust when analyzing the time period 2014-2018. These half-ellipses consist of an alongstrike continuous band of microseismicity that parallels the coastline at depths of 30 to $45 \mathrm{~km}$ on the plate interface, as well as two along-strike separators where seismicity extends significantly further updip and towards the trench. By prescribing frictionally strong "asperities" of high interplate locking in constrained inversions of GPS data as well as in mechanical FEM models, we show that the existence of such asperities on the Central Chilean plate interface can explain the observed seismicity patterns together with the observed upper plate deformation. 
According to our model, continued interseismic loading of strong asperities leads to a gradual buildup of stress concentrations along their downdip edges. These stress concentrations eventually evoke aseismic creep driving continuous microseismicity from some time in the late part of the interseismic stage onwards. The narrow along-strike separators between asperities seem to be controlled by regions of increased roughness and/or hydration on the incoming Nazca Plate, which effect elevated creep that often occurs in transient bursts that drive swarm-like earthquake sequences.

Our conceptual model implies that valuable information about the segmentation of megathrust faults can be obtained from the analysis of seismicity distributions, provided that the analyzed region is in a sufficiently late part of the interseismic stage, and that the observational timespan is long enough to capture the episodic activity of along-strike separators. We also demonstrated that including seismicity-derived geometries in GPS locking degree inversions may be a path towards improving the resolution of future plate interface interseismic models. In combination with frictional models informed by seismic data, this opens new avenues for determining the extent of asperities near the trench, where coupling models are usually ill-constrained. Lastly, seismicity may also be able to provide information about clamped asperities in situations where long-term postseismic processes from adjacent segments obscure highly locked patches in the GPS data.

\section{Acknowledgments}

We thank Hans Agurto-Detzel and two anonymous reviewers for comments on an earlier version of the manuscript, and Bernd Schurr for valuable discussions. The seismic waveform data that was used to compile the earthquake catalog was retrieved from the IRIS webpage (http://www.ds.iris.edu/ds/nodes/dmc/), and came from the networks C1 (Universidad de Chile, 2013), C (no DOI available), II (Scripps Institution Of Oceanography, 1986), G (Institut de Physique du Globe de Paris \& Ecole et Observatoire des Sciences de la Terre de Strasbourg (EOST)) and WA (no DOI available). Moment tensors shown in Figure 2 were retrieved from the globalCMT (https://www.globalcmt.org/) and GEOFON (https://geofon.gfz-potsdam.de/eqinfo/) databases. Seismic data processing was done with ObsPy (Beyreuther et al., 2010), figures were plotted with Matplotlib (Hunter, 2007) libraries, including Basemap (https://matplotlib.org/basemap/). M.M. acknowledges support from FONDECYT 1181479, the Millennium Nucleus NC160025, ANILLO ACT192169, and CONICYT/FONDAP 15110017. R.B. acknowledges funding from ANID, Chile through grant ANID/FONDECYT/3190322.

\section{References}

Aagaard, B.T., Knepley, M.G., Williams, C.A., 2013. A domain decomposition approach to implementing fault slip in finiteelement models of quasi-static and dynamic crustal deformation. Journal of Geophysical Research: Solid Earth 118, 30593079. doi:10.1002/jgrb.50217.

Ader, T., Avouac, J.P., Liu-Zeng, J., Lyon-Caen, H., Bollinger, L., Galetzka, J., Genrich, J., Thomas, M., Chanard, K., Sapkota, S.N., Rajaure, S., Shrestha, P., Ding, L., Flouzat, M., 2012. Convergence rate across the Nepal Himalaya and interseismic coupling on the Main Himalayan Thrust: Implications for seismic hazard. Journal of Geophysical Research: Solid Earth 117, 1-16. doi:10.1029/2011JB009071.

Agurto-Detzel, H., Font, Y., Charvis, P., Régnier, M., Rietbrock, A., Ambrois, D., Paulatto, M., Alvarado, A., Beck, S., Courboulex, F., De Barros, L., Deschamps, A., Hernandez, M.J., Hernandez, S., Hoskins, M., León-Ríos, S., Lynner, C., Meltzer, A., Mercerat, E.D., Michaud, F., Nocquet, J.M., Rolandone, F., Ruiz, M., Soto-Cordero, L., 2019. Ridge subduction and afterslip control aftershock distribution of the $2016 \mathrm{Mw} 7.8$ Ecuador earthquake. Earth and Planetary Science Letters 520, 63-76. doi:10.1016/j.epsl.2019.05.029.

Almeida, R., Lindsey, E.O., Bradley, K., Hubbard, J., Mallick, R., Hill, E.M., 2018. Can the Updip Limit of Frictional Locking on Megathrusts Be Detected Geodetically? Quantifying the Effect of Stress Shadows on Near-Trench Coupling. Geophysical Research Letters 45, 4754-4763. doi:10.1029/2018GL077785.

Anderson, M., Alvarado, P., Zandt, G., Beck, S., 2007. Geometry and brittle deformation of the subducting Nazca Plate, Central Chile and Argentina. Geophysical Journal International 171, 419-434. doi:10.1111/j.1365-246X.2007.03483.x.

Angermann, D., Klotz, J., Reigber, C., 1999. Space-geodetic estimation of the Nazca-South America Euler vector. Earth and Planetary Science Letters 171, 329-334. doi:10.1016/S0012-821X(99)00173-9.

Barbot, S., 2019. Slow-slip, slow earthquakes, period-two cycles, full and partial ruptures, and deterministic chaos in a single asperity fault. Tectonophysics 768, 228171. doi:https://doi.org/10.1016/j.tecto.2019.228171.

Barrientos, S., Vera, E., Alvarado, P., Monfret, T., 2004. Crustal seismicity in central Chile. Journal of South American Earth Sciences 16, 759-768. doi:10.1016/j.jsames.2003.12.001. 
Bassett, D., Watts, A.B., 2015. Gravity anomalies, crustal structure, and seismicity at subduction zones: 1. Seafloor roughness and subducting relief. Geochemistry, Geophysics, Geosystems 16, 1508-1540. doi:10.1002/2014GC005685.Key.

Béjar-Pizarro, M., Socquet, A., Armijo, R., Carrizo, D., Genrich, J., Simons, M., 2013. Andean structural control on interseismic coupling in the North Chile subduction zone. Nature Geoscience 6, 462-467. doi:10.1038/ngeo1802.

Beyreuther, M., Barsch, R., Krischer, L., Megies, T., Behr, Y., Wassermann, J., 2010. ObsPy: A Python Toolbox for Seismology. Seismological Research Letters 81, 530-533. doi:10.1785/gssrl.81.3.530.

Bletery, Q., Thomas, A.M., Rempel, A.W., Karlstrom, L., Sladen, A., De Barros, L., 2016. Mega-earthquakes rupture flat megathrusts. Science 354, 1027-1031. doi:10.1126/science.aag0482.

Bostock, M.G., Christensen, N.I., Peacock, S.M., 2019. Seismicity in Cascadia. Lithos 332-333, 55-66. doi:10.1016/j.lithos.2019.02.019.

Bravo, F., Koch, P., Riquelme, S., Fuentes, M., Campos, J., 2019. Slip Distribution of the 1985 Valparaíso Earthquake Constrained with Seismic and Deformation Data. Seismological Research Letters 9, 1-9. doi:10.1785/0220180396.

Brooks, B.A., Bevis, M., Smalley, R., Kendrick, E., Manceda, R., Lauría, E., Maturana, R., Araujo, M., 2003. Crustal motion in the Southern Andes (26-36S): Do the Andes behave like a microplate? Geochemistry, Geophysics, Geosystems 4, 1-14. doi:10.1029/2003GC000505.

Bürgmann, R., Kogan, M.G., Steblov, G.M., Hilley, G., Levin, V., Apel, E., 2005. Interseismic coupling and asperity distribution along the Kamchatka subduction zone. Journal of Geophysical Research 110, B07405. doi:10.1029/2005JB003648.

Carvajal, M., Cisternas, M., Catalán, P.A., 2017. Source of the 1730 Chilean earthquake from historical records: Implications for the future tsunami hazard on the coast of Metropolitan Chile. Journal of Geophysical Research 122, 3648-3660. doi:10.1002/2017JB014063.

Chlieh, M., Avouac, J.P., Sieh, K., Natawidjaja, D.H., Galetzka, J., 2008. Heterogeneous coupling of the Sumatran megathrust constrained by geodetic and paleogeodetic measurements. Journal of Geophysical Research 113 , B05305. doi:10.1029/2007JB004981.

Chlieh, M., De Chabalier, J.B., Ruegg, J.C., Armijo, R., Dmowska, R., Campos, J., Feigl, K.L., 2004. Crustal deformation and fault slip during the seismic cycle in the North Chile subduction zone, from GPS and InSAR observations. Geophysical Journal International 158, 695-711. doi:10.1111/j.1365-246X.2004.02326.x.

Chlieh, M., Perfettini, H., Tavera, H., Avouac, J.P., Remy, D., Nocquet, J.M., Rolandone, F., Bondoux, F., Gabalda, G., Bonvalot, S., 2011. Interseismic coupling and seismic potential along the Central Andes subduction zone. Journal of Geophysical Research: Solid Earth 116, B12405. doi:10.1029/2010JB008166.

Cloos, M., 1992. Thrust-type subduction-zone earthquakes and seamount asperities: a physical model for seismic rupture. Geology 20, 601-604.

Comte, D., Pardo, M., 1991. Reappraisal of great historical earthquakes in the northern Chile and southern Peru seismic gaps. Natural Hazards 4, 23-44. doi:10.1007/BF00126557.

Contreras-Reyes, E., Carrizo, D., 2011. Control of high oceanic features and subduction channel on earthquake ruptures along the Chile-Peru subduction zone. Physics of the Earth and Planetary Interiors 186, 49-58. doi:10.1016/j.pepi.2011.03.002.

Corbi, F., Funiciello, F., Brizzi, S., Lallemand, S., Rosenau, M., 2017. Control of asperities size and spacing on seismic behavior of subduction megathrusts. Geophysical Research Letters 44, 8227-8235. doi:10.1002/2017GL074182.

Das, S., Henry, C., 2003. Spatial relation between main earthquake slip and its aftershock distribution. Reviews of Geophysics 41, 1013. doi:10.1029/2002RG000119.

Dmowska, R., Li, V.C., 1982. A mechanical model of precursory source processes for some large earthquakes. Geophysical Research Letters 9, 393-396. doi:10.1029/GL009i004p00393.

Feng, L., Newman, A.V., Protti, M., Gonzlez, V., Jiang, Y., Dixon, T.H., 2012. Active deformation near the Nicoya Peninsula, northwestern Costa Rica, between 1996 and 2010: Interseismic megathrust coupling. Journal of Geophysical Research: Solid Earth 117, 1-23. doi:10.1029/2012JB009230.

Fujiwara, T., Kodaira, S., No, T., Kaiho, Y., Takahashi, N., Kaneda, Y., 2011. The 2011 Tohoku-oki Earthquake : Displacement reaching the trench axis. Science 334, 1240.

Goebel, T.H., Becker, T.W., Schorlemmer, D., Stanchits, S., Sammis, C.G., Rybacki, E., Dresen, G., 2012. Identifying fault heterogeneity through mapping spatial anomalies in acoustic emission statistics. Journal of Geophysical Research $117,1-18$. doi:10.1029/2011JB008763.

Hayes, G.P., Moore, G.L., Portner, D.E., Hearne, M., Flamme, H., Furtney, M., Smoczyk, G.M., 2018. Slab2, a comprehensive subduction zone geometry model. Science 362, 58-61. doi:10.1126/science.aat4723.

Hayes, G.P., Wald, D.J., Johnson, R.L., 2012. Slab1.0: A three-dimensional model of global subduction zone geometries. Journal of Geophysical Research 117, 1-15. doi:10.1029/2011JB008524.

Holtkamp, S., Brudzinski, M.R., 2014. Megathrust earthquake swarms indicate frictional changes which delimit large earthquake ruptures. Earth and Planetary Science Letters 390, 234-243. doi:10.1016/j.epsl.2013.10.033.

von Huene, R., Scholl, D.W., 1991. Observations at convergent margins concerning sediment subduction, subduction erosion, and the growth of continental crust. Reviews of Geophysics 29, 279-316. doi:10.1029/91RG00969.

Hunter, J.D., 2007. Matplotlib: A 2d graphics environment. Computing in Science \& Engineering 9, 90-95. doi:10.1109/MCSE.2007.55.

Ide, S., Baltay, A., Beroza, G.C., 2011. Shallow dynamic overshoot and energetic deep rupture in the 2011 M w 9.0 Tohoku-Oki earthquake. Science 332, 1426-1429. doi:10.1126/science.1207020.

Institut de Physique du Globe de Paris \& Ecole et Observatoire des Sciences de la Terre de Strasbourg (EOST), . GEOSCOPE - French Global Network of broadband seismic stations. doi:10.18715/GEOSCOPE.G.

Jiang, J., Lapusta, N., 2017. Connecting depth limits of interseismic locking, microseismicity, and large earthquakes in models of long-term fault slip. Journal of Geophysical Research: Solid Earth 122, 6491-6523. doi:10.1002/2017JB014030. 
Kanamori, H., 1981. The Nature of Seismicity Patterns Before Large Earthquakes, in: Earthquake Prediction, pp. 1-19. doi:10.1029/me004p0001.

Kendrick, E., Bevis, M., Smalley, R., Brooks, B., Vargas, R.B., Lauría, E., Fortes, L.P.S., 2003. The Nazca-South America Euler vector and its rate of change. Journal of South American Earth Sciences 16, 125-131. doi:10.1016/S0895-9811(03)00028-2.

Klotz, J., Khazaradze, G., Angermann, D., Reigber, C., Perdomo, R., Cifuentes, O., 2001. Earthquake cycle dominates contemporary crustal deformation in Central and Southern Andes. Earth and Planetary Science Letters $193,437-446$. doi:10.1016/S0012-821X(01)00532-5.

Lallemand, S., Peyret, M., van Rijsingen, E., Arcay, D., Heuret, A., 2018. Roughness Characteristics of Oceanic Seafloor Prior to Subduction in Relation to the Seismogenic Potential of Subduction Zones. Geochemistry, Geophysics, Geosystems 19, 2121-2146. doi:10.1029/2018GC007434.

Lange, D., Geersen, J., Barrientos, S., Moreno, M., Grevemeyer, I., Contreras-Reyes, E., Kopp, H., 2016. Aftershock seismicity and tectonic setting of the 2015 September $16 \mathrm{Mw} 8.3$ Illapel earthquake, Central Chile. Geophysical Journal International 206, 1424-1430. doi:10.1093/gji/ggw218.

Lange, D., Tilmann, F., Barrientos, S., Contreras-Reyes, E., Methe, P., Moreno, M., Heit, B., Agurto-Detzel, H., Bernard, P., Vilotte, J.P., Beck, S.L., 2012. Aftershock seismicity of the 27 February $2010 \mathrm{Mw} 8.8$ Maule earthquake rupture zone. Earth and Planetary Science Letters 317-318, 413-425. doi:10.1016/j.epsl.2011.11.034.

Lay, T., Ammon, C.J., Kanamori, H., Xue, L., Kim, M.J., 2011. Possible large near-trench slip during the 2011 M w 9.0 off the Pacific coast of Tohoku Earthquake. Earth, Planets and Space 63, 687-692. doi:10.5047/eps.2011.05.033.

Lay, T., Kanamori, H., 1981. An asperity model for large earthquake sequences. Earthquake Prediction , $579-592$.

Lay, T., Kanamori, H., Ammon, C.J., Koper, K.D., Hutko, A.R., Ye, L., Yue, H., Rushing, T.M., 2012. Depth-varying rupture properties of subduction zone megathrust faults. Journal of Geophysical Research 117, B04311. doi:10.1029/2011JB009133.

Li, S., Moreno, M., Bedford, J.R., Rosenau, M., Oncken, O., 2015. Revisiting viscoelastic effects on interseismic deformation and locking degree: A case study of the peru-north chile subduction zone. Journal of Geophysical Research $120,4522-4538$. doi:10.1002/2015JB011903.

Lomnitz, C., 2004. Major Earthquakes of Chile: A Historical Survey, 1535-1960. Seismological Research Letters 75, 368-378. doi:10.1785/gssrl.75.3.368.

Loveless, J.P., Meade, B.J., 2016. Two decades of spatiotemporal variations in subduction zone coupling offshore Japan. Earth and Planetary Science Letters 436, 19-30. doi:10.1016/j.epsl.2015.12.033.

Marot, M., Monfret, T., Pardo, M., Ranalli, G., Nolet, G., 2013. A double seismic zone in the subducting Juan Fernandez Ridge of the Nazca Plate (32S), central Chile. Journal of Geophysical Research 118, 3462-3475. doi:10.1002/jgrb.50240.

Mavrommatis, A.P., Segall, P., Johnson, K.M., 2017. A Physical Model for Interseismic Erosion of Locked Fault Asperities. Journal of Geophysical Research: Solid Earth 122, 8326-8346. doi:10.1002/2017JB014533.

Métois, M., Socquet, A., Vigny, C., 2012. Interseismic coupling, segmentation and mechanical behavior of the central Chile subduction zone. Journal of Geophysical Research: Solid Earth 117, B03406. doi:10.1029/2011JB008736.

Métois, M., Vigny, C., Socquet, A., 2016. Interseismic Coupling, Megathrust Earthquakes and Seismic Swarms Along the Chilean Subduction Zone (3818S). Pure and Applied Geophysics 173, 1431-1449. doi:10.1007/s00024-016-1280-5.

Mogi, K., 1969. Some features of recent seismic activity in and near Japan(2): Activity before and after great earthquakes. Bull. Earthquake Res. Inst. Univ. Tokyo 47, 395-417.

Mogi, K., 1979. Two kinds of seismic gaps. Pure and Applied Geophysics 117, 1172-1186. doi:10.1007/BF00876213.

Moreno, M., Haberland, C., Oncken, O., Rietbrock, A., Angiboust, S., Heidbach, O., 2014. Locking of the Chile subduction zone controlled by fluid pressure before the 2010 earthquake. Nature Geoscience 7, 292-296. doi:10.1038/ngeo2102.

Moreno, M., Li, S., Melnick, D., Bedford, J.R., Baez, J.C., Motagh, M., Metzger, S., Vajedian, S., Sippl, C., Gutknecht, B.D., Contreras-Reyes, E., Deng, Z., Tassara, A., Oncken, O., 2018. Chilean megathrust earthquake recurrence linked to frictional contrast at depth. Nature Geoscience 11, 285-290. doi:10.1038/s41561-018-0089-5.

Moreno, M., Melnick, D., Rosenau, M., Baez, J., Klotz, J., Oncken, O., Tassara, A., Chen, J., Bataille, K., Bevis, M., Socquet, A., Bolte, J., Vigny, C., Brooks, B., Ryder, I., Grund, V., Smalley, B., Carrizo, D., Bartsch, M., Hase, H., 2012. Toward understanding tectonic control on the M w 8.82010 Maule Chile earthquake. Earth and Planetary Science Letters 321-322, 152-165. doi:10.1016/j.epsl.2012.01.006.

Moreno, M., Melnick, D., Rosenau, M., Bolte, J., Klotz, J., Echtler, H., Baez, J., Bataille, K., Chen, J., Bevis, M., Hase, H., Oncken, O., 2011. Heterogeneous plate locking in the South-Central Chile subduction zone: Building up the next great earthquake. Earth and Planetary Science Letters 305, 413-424. doi:10.1016/j.epsl.2011.03.025.

Moreno, M., Rosenau, M., Oncken, O., 2010. 2010 Maule earthquake slip correlates with pre-seismic locking of Andean subduction zone. Nature 467, 198-202. doi:10.1038/nature09349.

Nadeau, R.M., McEvilly, T.V., 1999. Fault slip rates at depth from recurrence intervals of repeating microearthquakes. Science 285, 718-721. doi:10.1126/science.285.5428.718.

Oleskevich, D.A., Hyndman, R.D., Wang, K., 1999. The updip and downdip limits to great subduction earthquakes: Thermal and structural models of Cascadia, south Alaska, SW Japan, and Chile. Journal of Geophysical Research 104, $14965-14991$. doi:10.1029/1999jb900060.

Pacheco, F., Sykes, R., Scholz, C.H., 1993. Nature of seismic coupling along simple plate boundaries of the subduction type. Journal of Geophysical Research 98, 14,133-14,159.

Perfettini, H., Avouac, J.P., Tavera, H., Kositsky, A., Nocquet, J.M., Bondoux, F., Chlieh, M., Sladen, A., Audin, L., Farber, D.L., Soler, P., 2010. Seismic and aseismic slip on the Central Peru megathrust. Nature 465, 78-81. doi:10.1038/nature09062.

Poli, P., Jeria, A.M., Ruiz, S., 2017. The Mw 8.3 lllapel earthquake (Chile): Preseismic and postseismic activity associated with hydrated slab structures. Geology 45, 247-250. doi:10.1130/G38522.1.

Ramos, V.A., Cristallini, E.O., Pérez, D.J., 2002. The Pampean flat-slab of the Central Andes. Journal of South American 
Earth Sciences 15, 59-78. doi:10.1016/S0895-9811(02)00006-8.

Ramos, V.A., Folguera, A., 2009. Andean flat-slab subduction through time. Geological Society, London, Special Publications 327, 31-54. doi:10.1144/sp327.3.

van Rijsingen, E., Funiciello, F., Corbi, F., Lallemand, S., 2019. Rough Subducting Seafloor Reduces Interseismic Coupling and Mega-Earthquake Occurrence: Insights From Analogue Models. Geophysical Research Letters 46, $3124-3132$. doi:10.1029/2018GL081272.

Ruiz, J., Contreras-Reyes, E., Ortega-Culaciati, F., Manríquez, P., 2018. Rupture process of the April 24, 2017, Mw 6.9 Valparaíso earthquake from the joint inversion of teleseismic body waves and near-field data. Physics of the Earth and Planetary Interiors 279, 1-14. doi:10.1016/j.pepi.2018.03.007.

Ruiz, S., Aden-Antoniow, F., Baez, J.C., Otarola, C., Potin, B., del Campo, F., Poli, P., Flores, C., Satriano, C., Leyton, F., Madariaga, R., Bernard, P., 2017. Nucleation Phase and Dynamic Inversion of the Mw 6.9 Valparaíso 2017 Earthquake in Central Chile. Geophysical Research Letters 44, 10,290-10,297. doi:10.1002/2017GL075675.

Ruiz, S., Madariaga, R., 2018. Historical and recent large megathrust earthquakes in Chile. Tectonophysics 733 , 37-56. doi:10.1016/j.tecto.2018.01.015.

Savage, J.C., 1983. A dislocation model of strain accumulation and release at a subduction zone. Journal of Geophysical Research 88, 4984-4996. doi:10.1029/JB088iB06p04984.

Schmalzle, G.M., McCaffrey, R., Creager, K.C., 2014. Central Cascadia subduction zone creep. Geochemistry, Geophysics, Geosystems 15, 1515-1532. doi:10.1002/2013GC005172.

Scholz, C.H., 1998. Earthquakes and friction laws. Nature 391, 37-42.

Scholz, C.H., Campos, J., 1995. On the mechanism of seismic decoupling and back arc spreading at subduction zones. Journal of Geophysical Research: Solid Earth 100, 22103-22115. doi:10.1029/95jb01869.

Schurr, B., Asch, G., Hainzl, S., Bedford, J.R., Hoechner, A., Palo, M., Wang, R., Moreno, M., Bartsch, M., Zhang, Y., Oncken, O., Tilmann, F., Dahm, T., Victor, P., Barrientos, S., Vilotte, J.P., 2014. Gradual unlocking of plate boundary controlled initiation of the 2014 Iquique earthquake. Nature 512, 299-302. doi:10.1038/nature13681.

Schurr, B., Moreno, M., Tréhu, A.M., Bedford, J., Kummerow, J., Li, S., Oncken, O., 2020. Forming a Mogi Doughnut in the Years Prior to and Immediately Before the 2014 M8.1 Iquique, Northern Chile, Earthquake. Geophysical Research Letters 47. doi:10.1029/2020GL088351.

Schwarz, G., 1978. Estimating the dimension of a model. The Annals of Statistics 6, 461-464. doi:10.1214/aos/1176348654.

Scripps Institution Of Oceanography, 1986. IRIS/IDA Seismic Network. International Federation of Digital Seismograph Networks. doi:https://doi.org/10.7914/SN/II.

Sippl, C., Schurr, B., Yuan, X., Mechie, J., Schneider, F.M., Gadoev, M., Orunbaev, S., Oimahmadov, I., Haberland, C., Abdybachaev, U., Minaev, V., Negmatullaev, S., Radjabov, N., 2013. Geometry of the Pamir-Hindu Kush intermediatedepth earthquake zone from local seismic data. Journal of Geophysical Research 118, 1438-1457. doi:10.1002/jgrb.50128.

Soto-Cordero, L., Meltzer, A., Bergman, E., Hoskins, M., Stachnik, J.C., AgurtoDetzel, H., Alvarado, A., Beck, S., Charvis, P., Font, Y., Hayes, G.P., Hernandez, S., LeonRios, S., Lynner, C., Nocquet, J., Regnier, M., Rietbrock, A., Rolandone, F., Ruiz, M., 2020. Structural Control on Megathrust Rupture and Slip Behavior: Insights from the $2016 \mathrm{Mw} 7.8$ Pedernales Ecuador Earthquake. Journal of Geophysical Research: Solid Earth 125. doi:10.1029/2019JB018001.

Sparkes, R., Tilmann, F., Hovius, N., Hillier, J., 2010. Subducted seafloor relief stops rupture in South American great earthquakes: Implications for rupture behaviour in the 2010 Maule, Chile earthquake. Earth and Planetary Science Letters 298, 89-94. doi:10.1016/j.epsl.2010.07.029.

Sun, T., Saffer, D., Ellis, S., 2020. Mechanical and hydrological effects of seamount subduction on megathrust stress and slip. Nature Geoscience 13, 249-255. doi:10.1038/s41561-020-0542-0.

Sykes, L.R., 1971. Aftershock zones of great earthquakes, seismicity gaps, and earthquake prediction for Alaska and the Aleutians. Journal of Geophysical Research 76, 8021-8041. doi:10.1029/jb076i032p08021.

Tassara, A., Echaurren, A., 2012. Anatomy of the Andean subduction zone: Three-dimensional density model upgraded and compared against global-scale models. Geophysical Journal International 189, 161-168. doi:10.1111/j.1365246X.2012.05397.x.

Thurber, C.H., Eberhart-Phillips, D., 1999. Local earthquake tomography with flexible gridding. Computers and Geosciences 25, 809-818. doi:10.1016/S0098-3004(99)00007-2.

Tilmann, F., Zhang, Y., Moreno, M., Saul, J., Eckelmann, F., Palo, M., Deng, Z., Babeyko, A., Chen, K., Baez, J.C., Schurr, B., Wang, R., Dahm, T., 2016. The 2015 Illapel earthquake, central Chile: a type case for a characteristic earthquake ? Geophysical Research Letters 43, 574-583. doi:10.1002/2015GL066963.

Uchida, N., Bürgmann, R., 2019. Repeating Earthquakes. Annual Review of Earth and Planetary Sciences 47, 305-332. doi:10.1146/annurev-earth-053018-060119.

Uchida, N., Matsuzawa, T., 2013. Pre- and postseismic slow slip surrounding the 2011 Tohoku-oki earthquake rupture. Earth and Planetary Science Letters 374, 81-91. doi:10.1016/j.epsl.2013.05.021.

Universidad de Chile, 2013. Red Sismologica Nacional. International Federation of Digital Seismograph Networks. doi:https://doi.org/10.7914/SN/C1.

Vigny, C., Rudloff, A., Ruegg, J.C., Madariaga, R., Campos, J., Alvarez, M., 2009. Upper plate deformation measured by GPS in the Coquimbo Gap, Chile. Physics of the Earth and Planetary Interiors 175, 86-95. doi:10.1016/j.pepi.2008.02.013.

Vigny, C., Socquet, A., Peyrat, S., Ruegg, J.C., Metois, M., Madariaga, R., Morvan, S., Lancieri, M., Lacassin, R., Campos, J., Carrizo, D., Bejar-Pizarro, M., Barrientos, S., Armijo, R., Aranda, C., Valderas-Bermejo, M.C., Ortega, I., Bondoux, F., Baize, S., Lyon-Caen, H., Pavez, A., Vilotte, J.P., Bevis, M., Brooks, B., Smalley, R., Parra, H., Baez, J.C., Blanco, M., Cimbaro, S., Kendrick, E., 2011. The 2010 Mw 8.8 Maule mega-thrust earthquake of central Chile, monitored by GPS. Science 332, 1417-1422. doi:10.1126/science.1204132. 
Waldhauser, F., Ellsworth, W.L., 2000. A Double-difference Earthquake location algorithm: Method and application to the Northern Hayward Fault, California. Bulletin of the Seismological Society of America 90, 1353-1368. doi:10.1785/0120000006.

Wang, K., Bilek, S.L., 2014. Invited review paper: Fault creep caused by subduction of rough seafloor relief. doi:10.1016/j.tecto.2013.11.024.

Wang, K., Dixon, T., 2004. Coupling semantics and science in earthquake research. Eos 85, 180. doi:10.1029/2004EO180005. Wang, K., Huang, T., Tilmann, F., Peacock, S.M., Lange, D., 2020. Role of serpentinized mantle wedge in affecting megathrust seismogenic behavior in the area of the $2010 \mathrm{~m}=8.8$ maule earthquake. Geophysical Research Letters n/a, e2020GL090482. doi:https://doi.org/10.1029/2020GL090482.

Wang, K., Wada, I., Ishikawa, Y., 2004. Stresses in the subducting slab beneath southwest Japan and relation with plate geometry, tectonic forces, slab dehydration, and damaging earthquakes. Journal of Geophysical Research 109 , 1-15. doi:10.1029/2003JB002888.

Yarce, J., Sheehan, A.F., Nakai, J.S., Schwartz, S.Y., Mochizuki, K., Savage, M.K., Wallace, L.M., Henrys, S.A., Webb, S.C., Ito, Y., Abercrombie, R.E., Fry, B., Shaddox, H., Todd, E.K., 2019. Seismicity at the Northern Hikurangi Margin, New Zealand, and Investigation of the Potential Spatial and Temporal Relationships With a Shallow Slow Slip Event. Journal of Geophysical Research: Solid Earth 124, 4751-4766. doi:10.1029/2018JB017211. 

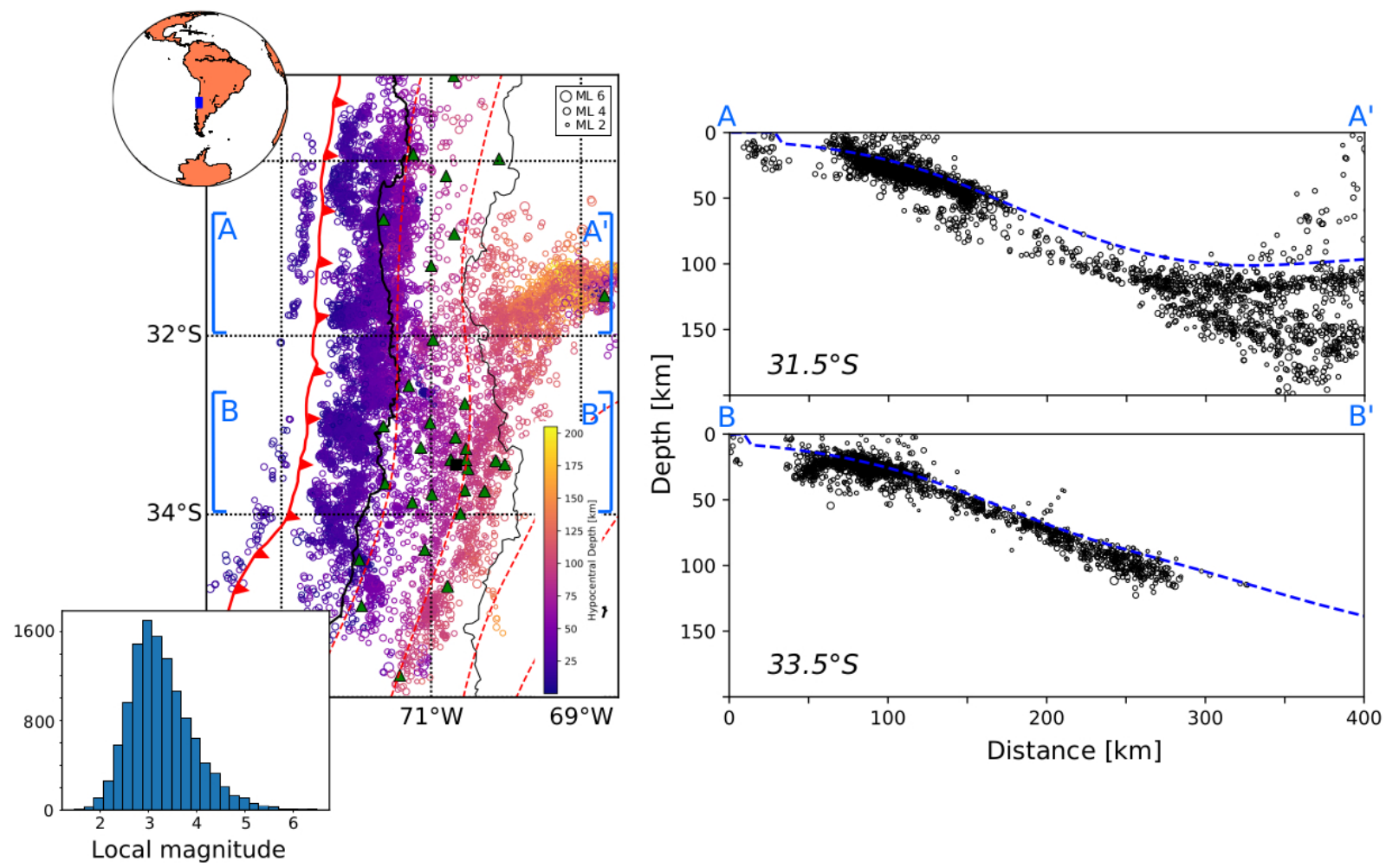

Figure 1: Summary of the microseismicity catalog for Central Chile. The left subplot shows a map view plot of event epicenters, color-coded by hypocentral depth. The solid, barbed red line marks the location of the trench, dashed red lines mark the 40, 80,120 and $160 \mathrm{~km}$ slab surface isodepth contours according to the slab2 model (Hayes et al., 2018). Green triangles mark the locations of the seismic stations that were used for determining the catalog, the black square marks the location of the city of Santiago de Chile. Blue brackets show the location and width of the two profiles plotted in the right subfigure. The right subplot shows two east-west profile projection of hypocenters, along swaths of $50 \mathrm{~km}$ half-width around the latitudes printed into the lower left of each profile. The blue dashed lines mark the slab surface according to the slab2 model. In both subfigures, the circles representing earthquake hypocenters are scaled to magnitude as shown in the upper right of the map view plot. 


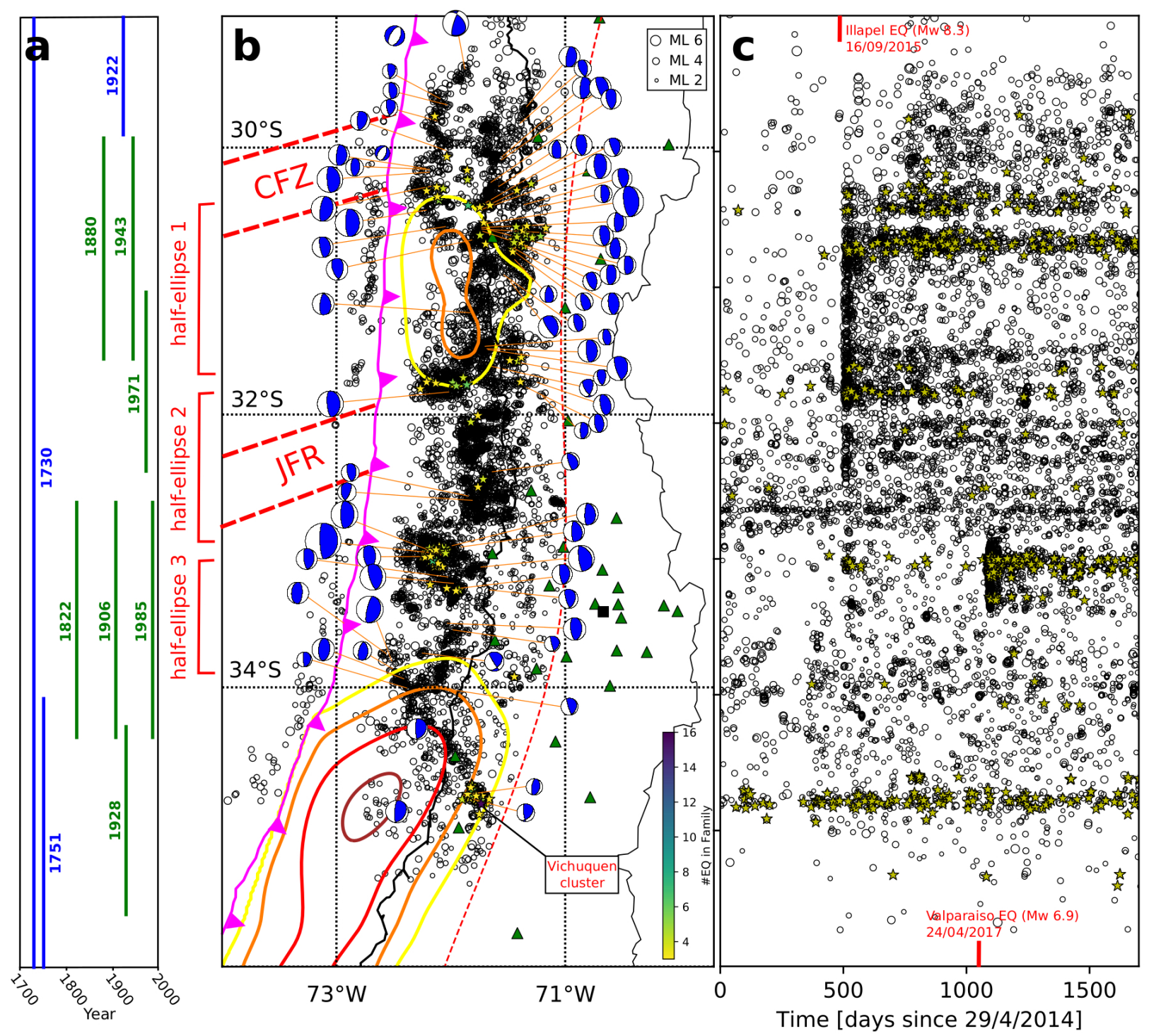

Figure 2: Characterization of plate interface seismicity in Central Chile. a) Historical earthquake rupture length estimates for the years 1700-2000, taken from Ruiz and Madariaga (2018). Blue lines mark earthquakes with $M_{w}>8.5$, earthquakes with magnitudes between 8 and 8.5 are shown in green. Slip areas for the two major earthquakes that occurred after the year 2000 are outlined in subfigure b. b) Map view plot of epicenters of shallow seismicity (hypocentral depths $<60 \mathrm{~km}$ ) from our catalog, covering the timespan mid-2014 to 2018. The sizes of the hollow black circles that denote epicenters are scaled with magnitude. Stars mark the location of families of repeating earthquakes, their color shows how many individual earthquakes are contained in each such family (see scale bar). Moment tensors for large events that occurred after 01/01/2016 (taken from the GEOFON and globalCMT databases) are shown with lower hemisphere beachball projections of their double-couple part, nearly all of them featuring low-angle thrusting. The size of the beachballs scales with $M_{w}$. The magenta solid line marks the location of the trench, whereas yellow, orange, red and brown solid lines mark the 2, 5, 10 and $20 \mathrm{~m}$ slip contours of the 2015 $M_{w} 8.3$ Illapel earthquake (to the north; from Tilmann et al., 2016) and the $2010 M_{w} 8.8$ Maule earthquake (to the south; from Moreno et al., 2012). Red dashed lines mark where prominent seafloor features on the lower plate (CFZ - Challenger Fracture Zone; JFR - Juan Fernández Ridge; see Figure S2) approximately impinge on the study area. As in Figure 1, green triangles mark the locations of used seismic stations, and the black square marks the city of Santiago de Chile. c) Time evolution of seismicity in our catalog. Yellow stars now mark individual events that belong to a repeater family. The origin times of the 2015 Illapel and the 2017 Valparaíso earthquakes are indicated with red markers. Note that due to sparse network coverage in that time, our catalog is incomplete in the northern part of the study area for the years 2014 and 2015 . Hence, the event numbers of the Illapel earthquake's immediate aftershock series are underestimated. 

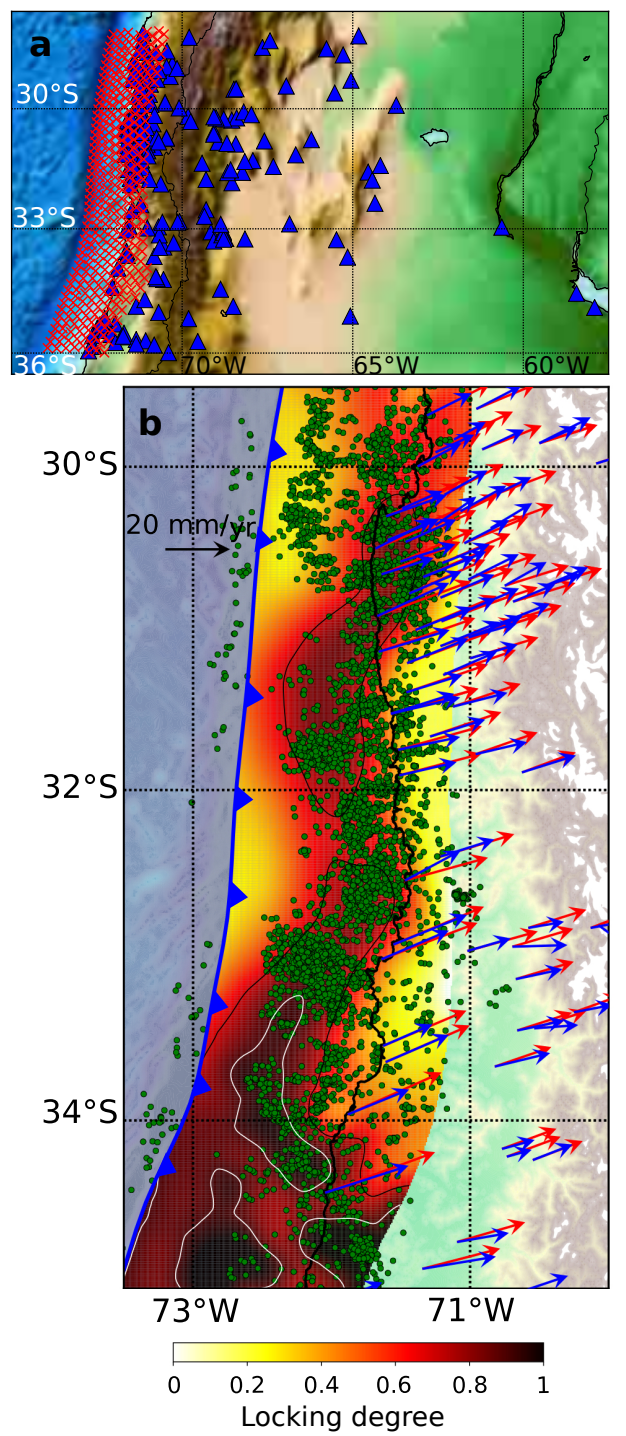

Figure 3: a) Distribution of GPS measurement sites and grid used for the locking inversions. Blue triangles correspond to GPS sites (refer to the text for a more detailed description of the data sources), red crosses are inversion nodes. b) Results of the unconstrained locking inversion. The distribution of interplate locking is shown, overlain onto the seismicity distribution from Figure $2 \mathrm{~b}$, represented by green circles. The arrows represent horizontal GPS observations (blue) and predictions from the shown model (red). Black arrow on the upper left is for scale $(20 \mathrm{~mm} / \mathrm{yr})$. Black and white contour lines trace locking degrees of 0.7 and 0.9 , respectively. 

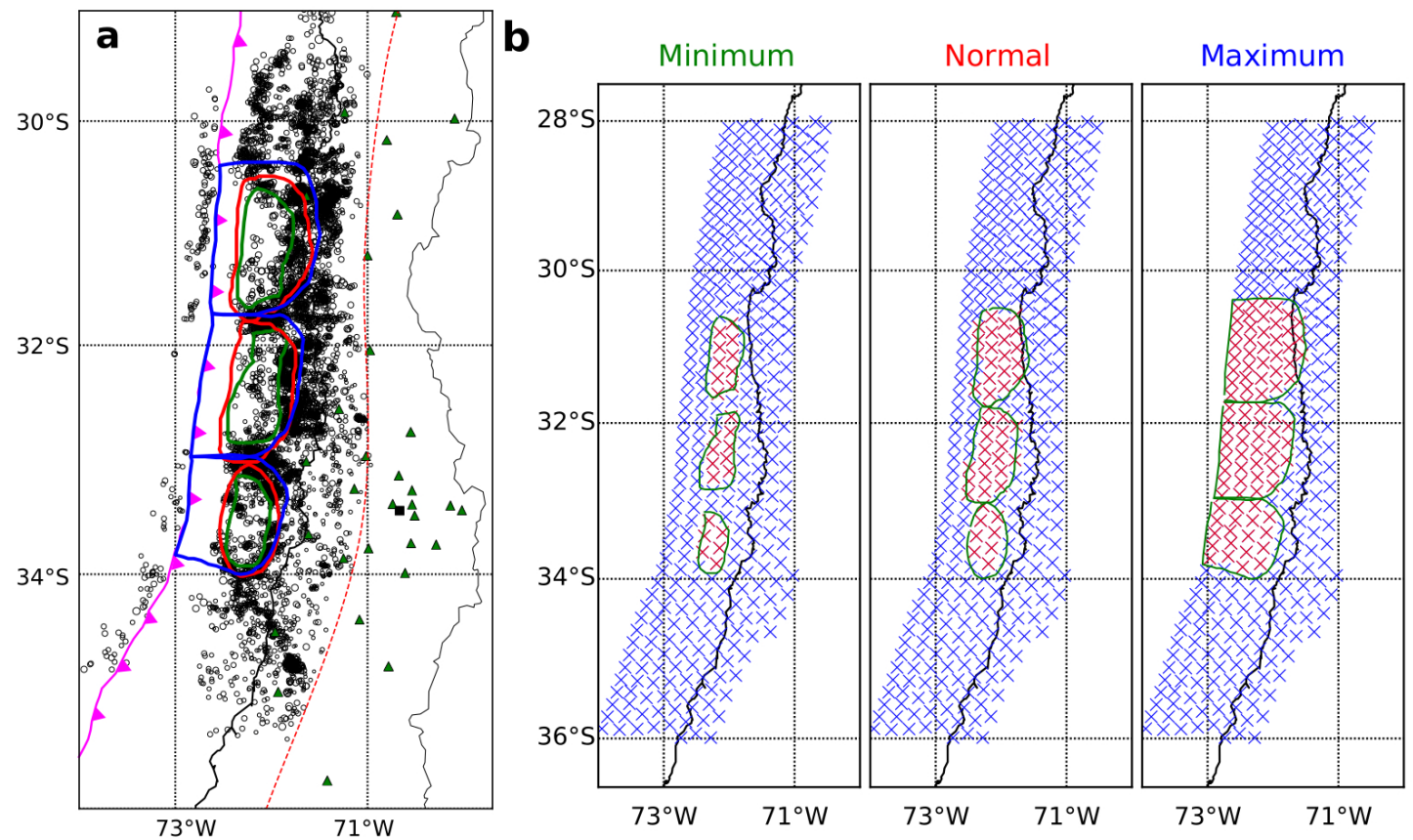

Figure 4: a) Distribution of plate interface seismicity (as in Figure 2b), and the three sets of potential asperities we fitted. Minimum size asperities are shown with green outlines, normal-sized ones in red and maximum-sized ones in blue. b) Implementation of these three sets of asperities into the grid used for the GPS-based locking inversions and the mechanical modeling. Red nodes belong to the asperities, which are shown with green outlines. 

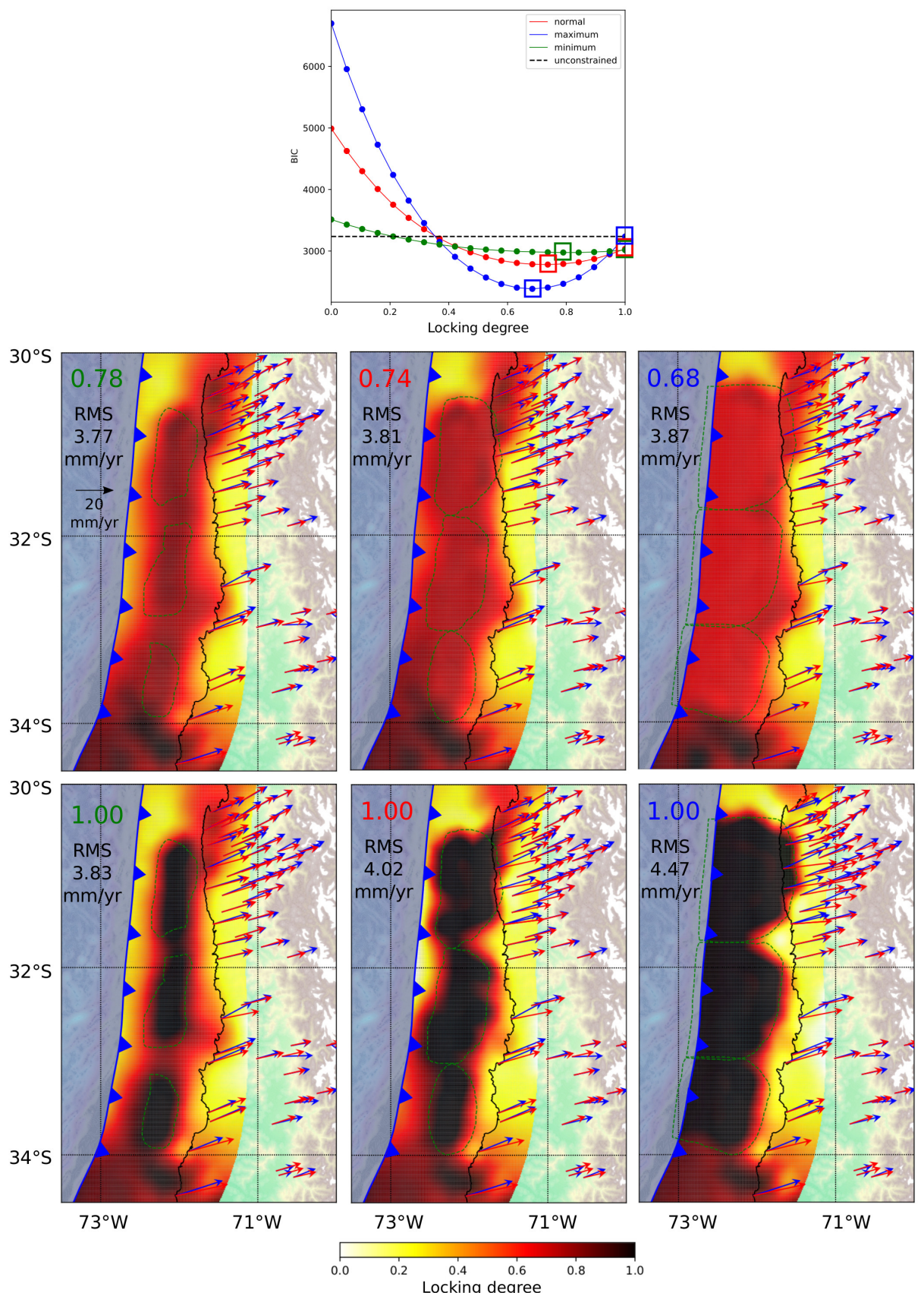

$73^{\circ} \mathrm{W}$

$71^{\circ} \mathrm{W}$

Figure 5: Results of constrained GPS inversions for interplate locking, fixing the nodes in the three sets of asperities shown in Figure 4. Uppermost subfigure: BIC values for different asperity sets with variation in the value of locking that in-asperity nodes were fixed to. The horizontal black dashed line represents the BIC for the unconstrained inversion (Figure 3b). The six values marked by squares are shown in the lower two rows of the figure. Middle row: Optimum-BIC models for the minimum (left), normal (middle) and maximum (right) asperities. The resulting interplate locking models are shown, with the outlines of the fixed-node asperities shown in green. The numbers in the upper left indicate the optimal coupling value for in-asperity nodes. Blue and red arrows represent data and model predictions, respectively. The black arrow in the left subfigure is for scale $(20 \mathrm{~mm} / \mathrm{yr})$. Lower row: Models for the three asperity sizes assuming complete locking inside the prescribed asperities. 


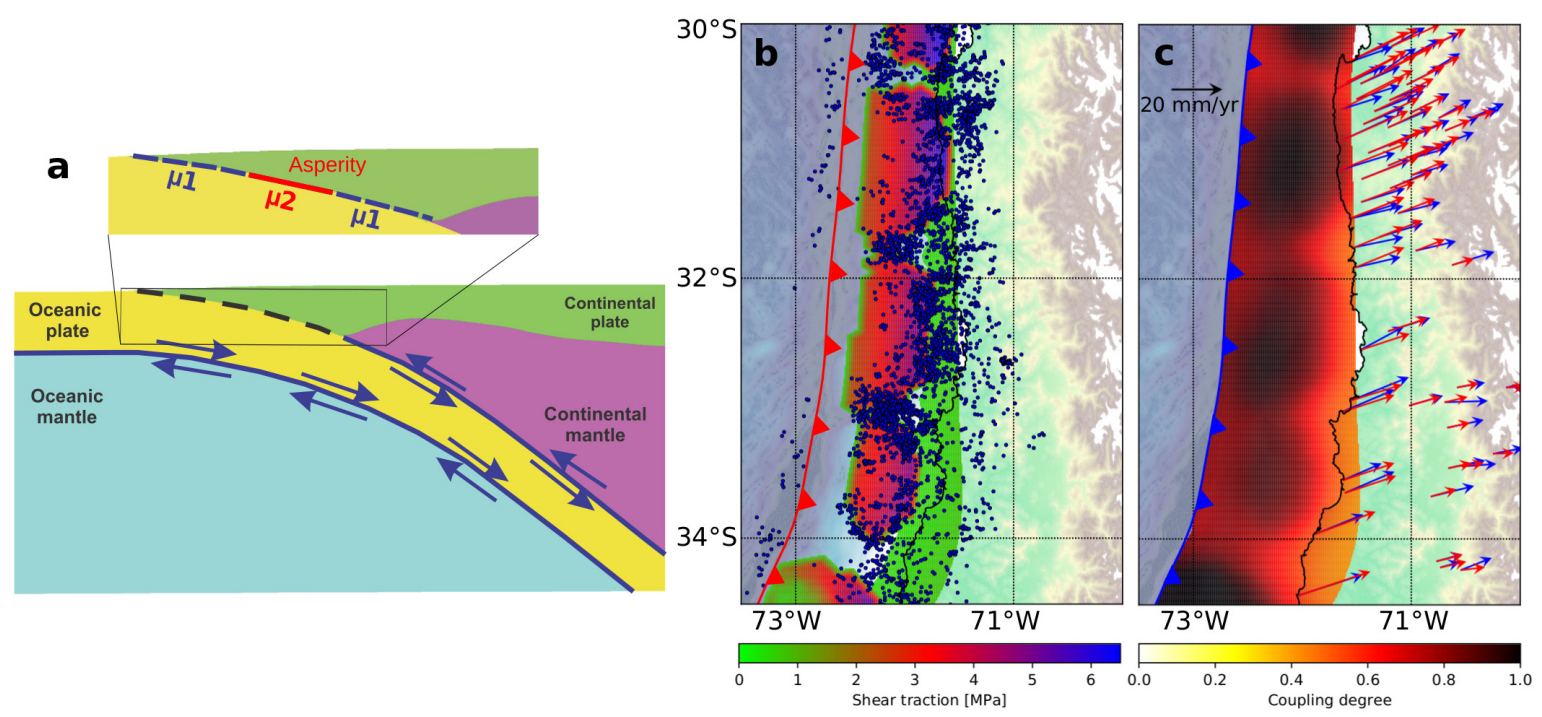

Figure 6: a) 2D principle sketch of the used simple mechanical model (which is 3D). Frictionless relative motion at plate convergence rate is imposed on the interfaces between Oceanic plate and Continental mantle and Oceanic plate and Oceanic mantle, respectively. On the interface between Oceanic and Continental plate, the frictional contact is made up by two different values for the friction parameterm $\mu 2$ inside the asperities (shown in Figure 4), $\mu 1$ on the rest of the plate interface. b) Output from the modelling: distribution of shear traction after 300 years of loading, with a frictional ratio of 0.1, with plate interface seismicity overlain. c) Prediction of interplate coupling from the modelling results, shown as in Figure 3b. 

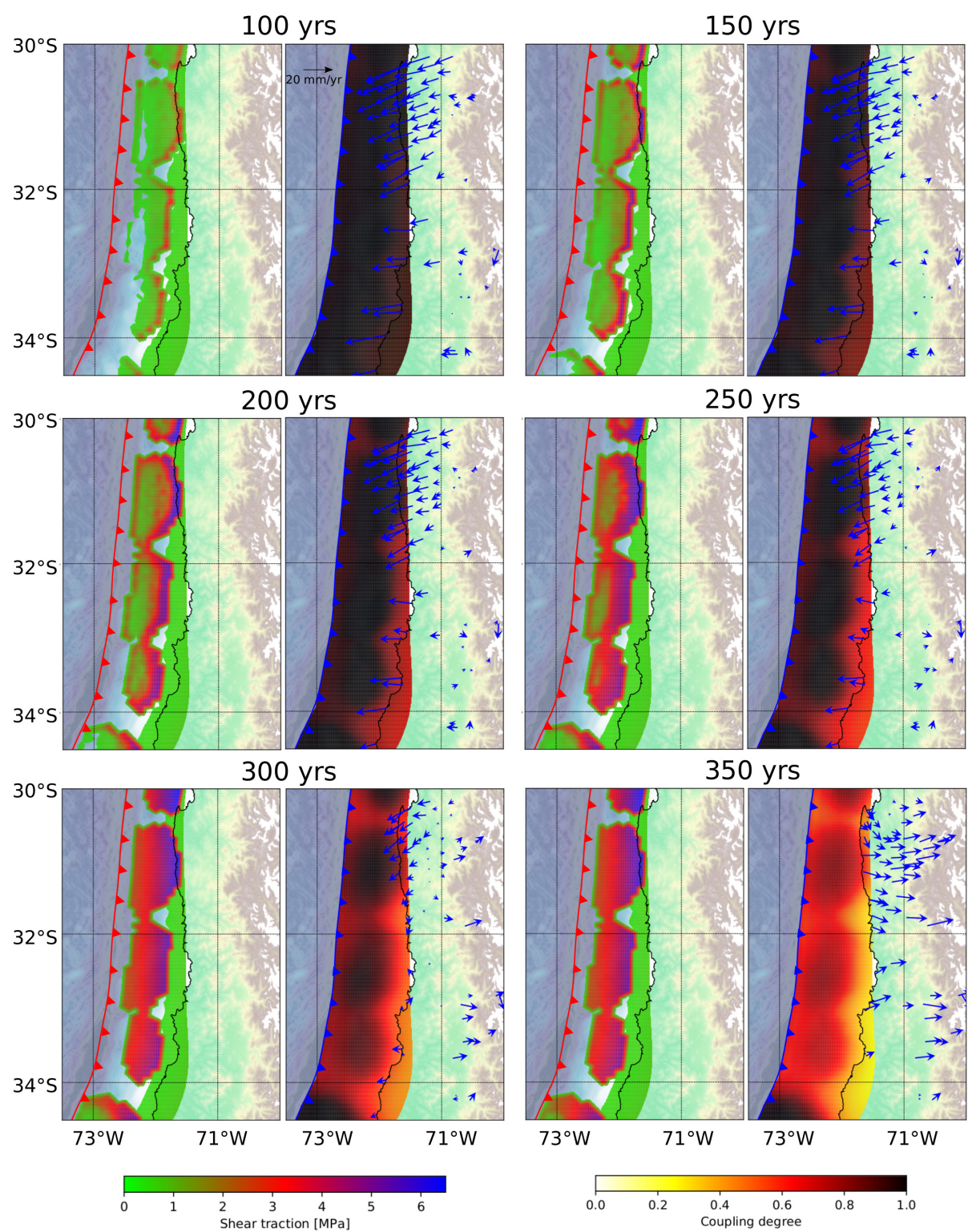

Figure 7: Temporal evolution of shear traction and interplate coupling distribution for a model with normal-sized asperities and a frictional ratio of 0.1. Blue arrows represent GPS residuals, the black arrow in the 100 yrs timestep is for scale (20 $\mathrm{mm} / \mathrm{yr})$. 


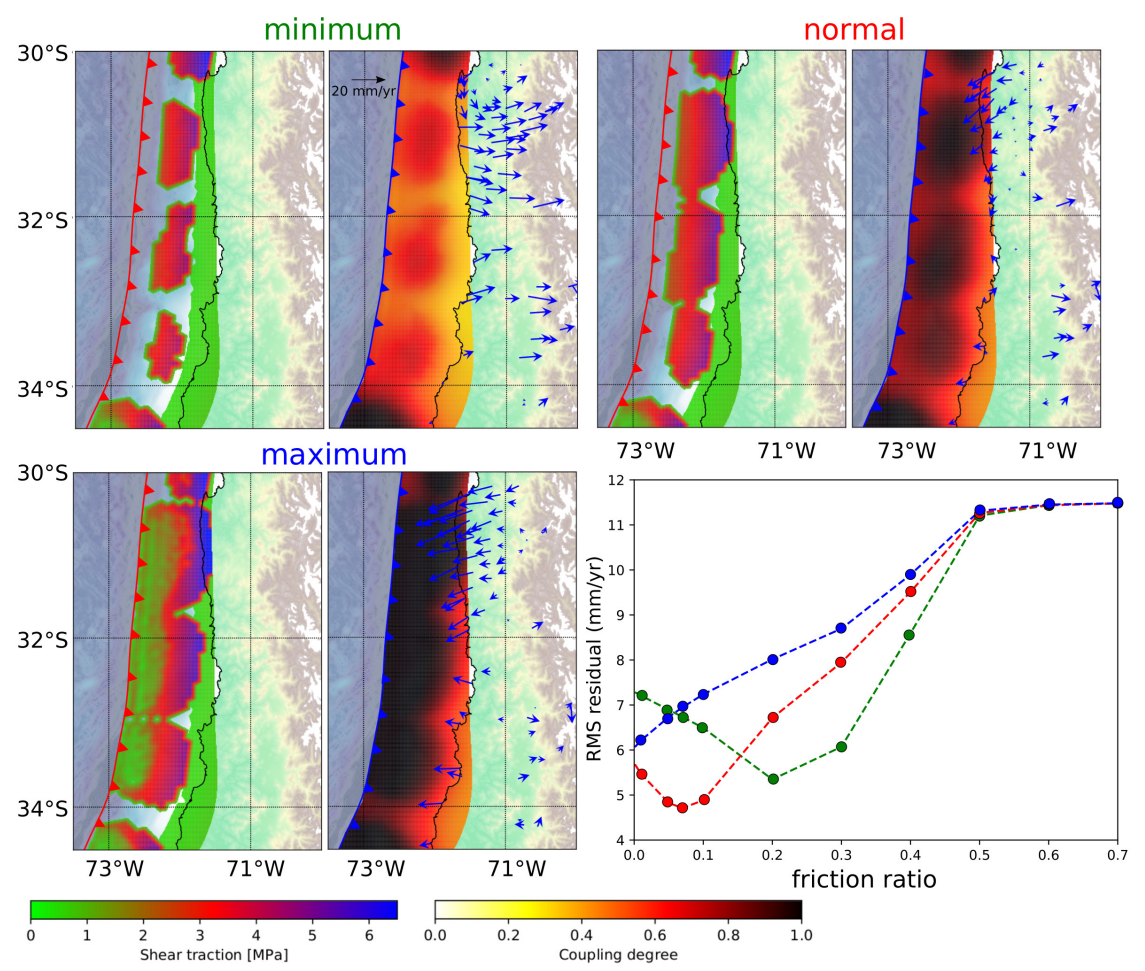

Figure 8: Comparison of $300 \mathrm{yr}$ timesteps for the three different asperity sizes and a frictional ratio of 0.1. Blue arrows show residuals between GPS observations and synthetically calculated displacements from the coupling models. The plot in the lower right shows the different displacement RMS residuals for runs with different frictional ratios, with the three different asperity sizes represented by the color of the curves (green - minimum; red - normal; blue -maximum). In all cases, the timestep of 300 years was evaluated for this plot. 


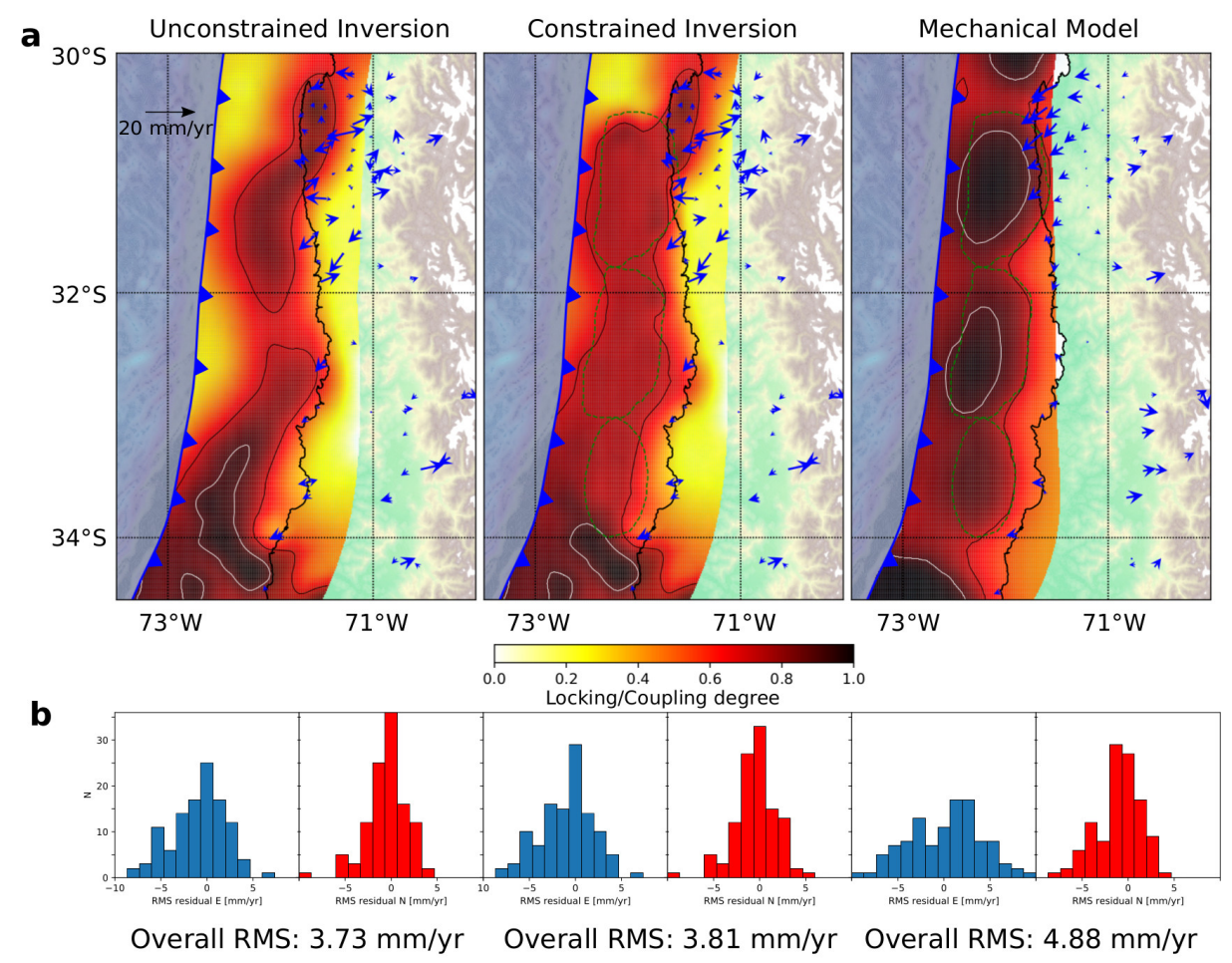

Figure 9: a) Summary of differently obtained interplate locking and coupling maps. Shown are results from the unconstrained inversion (left), the optimal constrained inversion with normal-sized prescribed asperities fixed to a locking value of 0.74 , and predictions from the mechanical modelling assuming the same asperity sizes and a frictional ratio of 0.1. Arrows represent GPS residuals, with the black arrow in the left plot for scale $(20 \mathrm{~mm} / \mathrm{yr})$. Black and white contour lines trace locking or coupling values of 0.7 and 0.9 , respectively (as in Figure 3). b) Histograms of GPS residuals for the E component (blue) and $\mathrm{N}$ component (red) for each of the presented models, as well as their overall RMS residual values. 